\title{
Circular RNA is a popular molecule in tumors of the digestive system (Review)
}

\author{
HAO-YING WANG ${ }^{1,2^{*}}$, YU-PING WANG ${ }^{1,2^{*}}$, XI ZENG $^{1,2^{*}}$, YA ZHENG $^{1,2}$, \\ QING-HONG GUO ${ }^{1,2}$, RUI JI ${ }^{1,2}$ and YONG-NING ZHOU ${ }^{1,2}$ \\ ${ }^{1}$ Department of Gastroenterology; ${ }^{2}$ Key Laboratory for Gastrointestinal Diseases of Gansu Province, \\ The First Hospital of Lanzhou University, Lanzhou, Gansu 730000, P.R. China
}

Received January 10, 2020; Accepted April 6, 2020

DOI: $10.3892 /$ ijo.2020.5054

\begin{abstract}
Most tumors of the digestive system, including esophageal, gastric, liver and colorectal cancer, are malignant tumors that are associated with rates of high morbidity and mortality. The lack of effective methods for early diagnosis is an important cause of poor prognosis for these malignancies. Circular RNAs (circRNAs) belong to a family of endogenous, covalently closed non-coding RNAs that are characterized as having no 5' cap structures or 3' poly-A tails. Shortly following discovery, circRNAs were considered to be a product of mis-splicing and have no significant biological function. However, in recent years, accumulating evidence is demonstrating that they serve key roles in tumorigenesis and have the potential to serve as diagnostic markers. The present article summarizes the biogenesis and function of circRNAs and reviews their role in seven common types of tumor of the digestive system whilst exploring their potential as tumor markers and the significant roles they can serve in the digestive system, in addition to providing a referencing point for future studies of digestive system malignancies.
\end{abstract}

\section{Contents}

1. Introduction

2. Biogenesis and function of circRNA

Correspondence to: Professor Yong-Ning Zhou, Key Laboratory for Gastrointestinal Diseases of Gansu Province, The First Hospital of Lanzhou University, 1 West Donggang Road, Lanzhou, Gansu 730000, P.R. China

E-mail: zhouyn@1zu.edu.cn

Dr Rui Ji, Department of Gastroenterology, The First Hospital of Lanzhou University, 1 West Donggang Road, Lanzhou, Gansu 730000, P.R. China

E-mail: jir@1zu.edu.cn

*Contributed equally

Key words: circular RNA, digestive system, cancer, biomarker, therapeutic targets
3. circRNA in digestive system malignancies

4. Non-coding RNAs in digestive system malignancies

5. Conclusions and perspectives

\section{Introduction}

Circular RNA (circRNA) is a common class of non-coding RNAs produced by back splicing, which is an unconventional splicing event and are characterized as having no $5^{\prime}$ end cap structures or $3^{\prime}$ end poly-adenylation tails (1). Although Sanger et al (2) discovered this special type of RNA molecule in 1976, scientists generally believed that it was a product of incorrect splicing and were generally neglected since. That was not until 2013, when Hansen et al (3) and Memczak et al (4) reported that circRNA served an endogenous role as a microRNA (miRNA) sponge, that gradually changed the perception of researchers. In recent years, with continuous advancements in sequencing technology, an increasing number of circRNAs have been discovered and subsequently studied. Accumulating evidence have suggested that circRNA serves a significant role in the progression of a number of diseases, including Alzheimer's disease, cardiovascular disease, diabetes and cancer (3-6). Since circRNA is highly conserved and is stably expressed in various tissues and bodily fluids, it can be applied to predict disease and evaluate the effect of diagnosis and treatment (7). However, the emerging role of circRNA as a biomarker in cancer is becoming particularly prominent.

Digestive system malignancies account for a large proportion of all cancer cases. According to the 2018 Global Cancer Statistics Report released by the World Health Organization, colorectal, gastric, hepatocellular and esophageal cancers were ranked amongst the top 10 in terms of morbidity (8), whilst colorectal, gastric, hepatocellular, esophageal and pancreatic cancers were ranked amongst the top 10 in terms of mortality (8). In addition, colorectal and stomach cancer are ranked amongst the top five in terms of both morbidity and mortality (8). These data suggested that digestive system malignancies have become a significant threat to global health. In recent decades, diagnosis and treatment of tumors of the digestive system have been markedly improved, where several novel strategies have been developed. However, since patients are frequently diagnosed at an advanced stage, the survival 
rate of patients with digestive system malignancies remain unsatisfactory.

In the present review, the biogenesis, function and role of circRNA in the development of tumors of the digestive system were summarized, where the possibility and emerging role of circRNA as a tumor marker in the digestive system was explored, providing a referencing point for the study of digestive system malignancies.

\section{Biogenesis and function of circRNA}

Biogenesis of circRNA. CircRNA is a non-coding RNA that is produced by two possible models of loop generation previously proposed by Jeck et al (9): i) Intron-pairing-driven circularization; and ii) lariat-driven circularization, both of which are widely accepted. Intron-pairing-driven circularization occurs as a result of complementary base pairing between different introns in the sequence, bringing adjacent exons to close proximity, following which the spliceosome cut away the adjacent exons and paired introns to form the circRNA. Lariat-driven circularization relies on the covalent interaction between the splice acceptor and donor, resulting in a circRNA containing the exon lariat (9). Intron circRNA is another subtype of circRNA discovered in recent years (10). The 11-nucleotide C-rich element and 7-nucleotide G-rich element in the parent gene of the intron circRNA combine to form a circular structure which are then spliced by the spliceosome (10). The spliceosome mechanism serves a significant role in the biogenesis of circRNA, which depends on trans-acting factors and cis-regulatory elements (11). Zhang et al (12) used four thiopurines to label newly generated RNA to reveal that low levels of circRNA may be a by-product of incomplete pre-RNA splicing, whilst the transcription of RNA polymerase II (pol II) occurred simultaneously with the formation of circRNA, suggesting that rapid extension of the strand may promote the reverse splicing of complementary paired sequences. In addition, the activity of pol II is strictly controlled by cis-regulatory elements (12). A number of circRNAs can be detected after pre-mRNA transcription is complete, suggesting that the biogenic process of circRNA may be post-transcriptional (13). In addition to pre-RNA and pol II, the biogenesis of circRNA is also regulated by a variety of proteins, enzymes, intron sequences and active elements. A previous study showed that RNA-binding proteins can also serve as regulators of circRNA production, which is a particularly prevalent mechanism observed during epithelial-mesenchymal transition (EMT) in tumors (14). The RNA helicase DExH-box helicase 9 (DHX9) specifically recognizes the reverse repeat Alu element, which is involved in the regulation of RNA post-transcriptional splicing (15). Alu elements are a class of functional sequences that are widely found in primates and are closely associated with the biogenesis of circRNAs (15). The expression levels of DHX9 affects the formation of splicing products, the deletion of which has been found to increase circRNA biogenesis of (15). In addition, exon circularization is dynamic process that is regulated by neighboring introns, where individual and flanking introns compete to regulate the formation of circRNA through base pairing (16). Modifications to the mRNA have been previously demonstrated to regulate transcription, alternative splicing, formation of advanced structures, translation and stability.
Tang et al (17) found that $\mathrm{N}^{6}$-methyladenosine (m6A) modification can promote the generation of circRNA carrying open reading frames in mouse male germ cells. In addition, the level of other circRNAs in tissues can also adversely affect the biogenesis of circRNA (18).

Function of circRNA. CircRNA can be classified into exon circRNA, exon-intron circRNA and intron circRNA, according to their origins $(19,20)$. Exon circRNA is generally more commonly observed in eukaryotes (19). Compared with corresponding linear RNA of the same sequence, circRNA is more stable and less susceptible to degradation by RNase $\mathrm{R}$ (21), which is one of the main factors for circRNA being considered as a potential biomarker.

CircRNA has a multitude of reported functions (Fig. 1), the most studied of which is its property as an endogenous competitive RNA to sponge miRNA (22). miR-7 is a widely studied miRNA that has been reported to participate in cell proliferation, differentiation, migration, invasion and a number of signaling pathways in various types of malignancies, including lung, breast and thyroid cancer (23-25). Hollensen et al (26) previously demonstrated that cerebellar degeneration-related autoantigen 1, antisense can (ciRS7 or CDR1AS) act as an negative upstream regulator of miR-7, downregulating miR-7 expression in cells. In recent years, an increasing number of studies have shown miRNA sponging to be the most common function of circRNA. In addition to sponging miRNA, complex interactions between circRNA and proteins have been observed in regulating biological processes. CircRNA can also act as a protein sponge to directly regulate the expression of functional proteins (27). Du et al (28) found that circular RNA-forkhead box O3 blocked cell cycle progression by forming a complex with p21 and cyclin dependent kinase $(\mathrm{Cdk}) 2$. By contrast, certain circular RNAs have been demonstrated to act synergistically with specific proteins in response to extracellular stimuli (29). Li et al (29) found that the synergy between circRNA and the immune factor interleukin enhancer binding factor 3 promoted cellular responses to viral infections. A small number of circRNAs have also been documented to encode genes that can be translated into proteins directly involved in the regulation of physiological functions (30). Circ-ZNF609 binds ribosomes via an internal ribosome entry site and translates into ZNF609 to regulate the proliferation of myoblasts (31). Yang et al (30) reported in 2017 that m6A drives the initiation of circRNA translation in human cells. CircRNA has also been shown to regulate the splicing of pre-RNA and the function of the parental gene $(10,16)$. This is mainly due to the role of some circRNAs located in the nucleus. For example, the circRNA ciankrd52 has been reported to interact with pol II to promote parental ankyrin repeat domain 52 pre-mRNA transcription (10). In summary, circRNA has a variety of biological functions, though this field of research remains incomplete (10).

\section{CircRNA in digestive system malignancies}

As an important subtype of non-coding RNA, circRNA has received considerable attention in cancer research in recent decades, where an increasing number of studies have shown that circRNA may serve significant roles in a multiple types of 


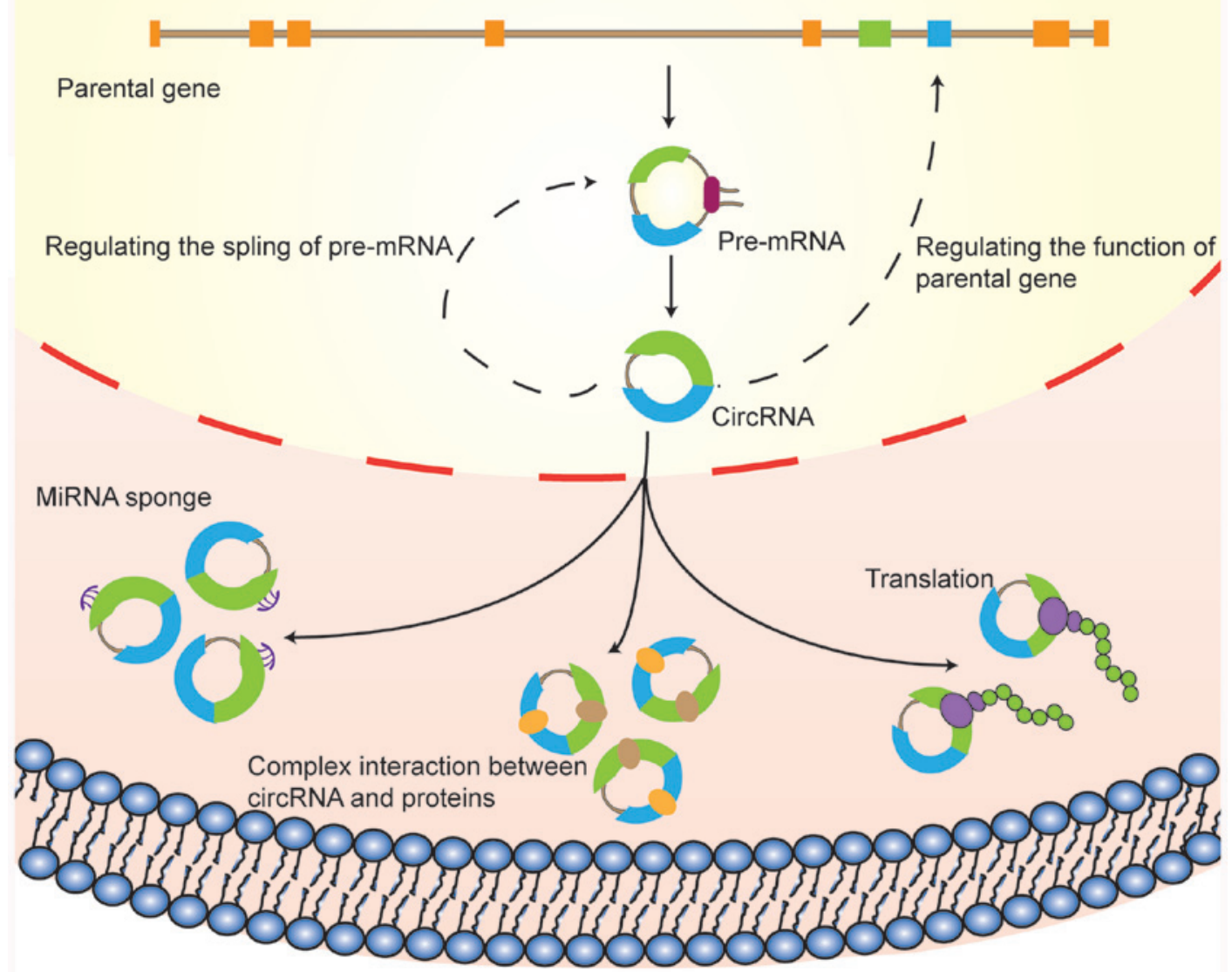

Figure 1. Function of circRNA. CircRNA has a variety of biological functions, including the regulation of pre-mRNA splicing and the function of parent genes, miRNA sponging, interactions with proteins and protein translation. CircRNA, circular RNA; miRNA, microRNA.

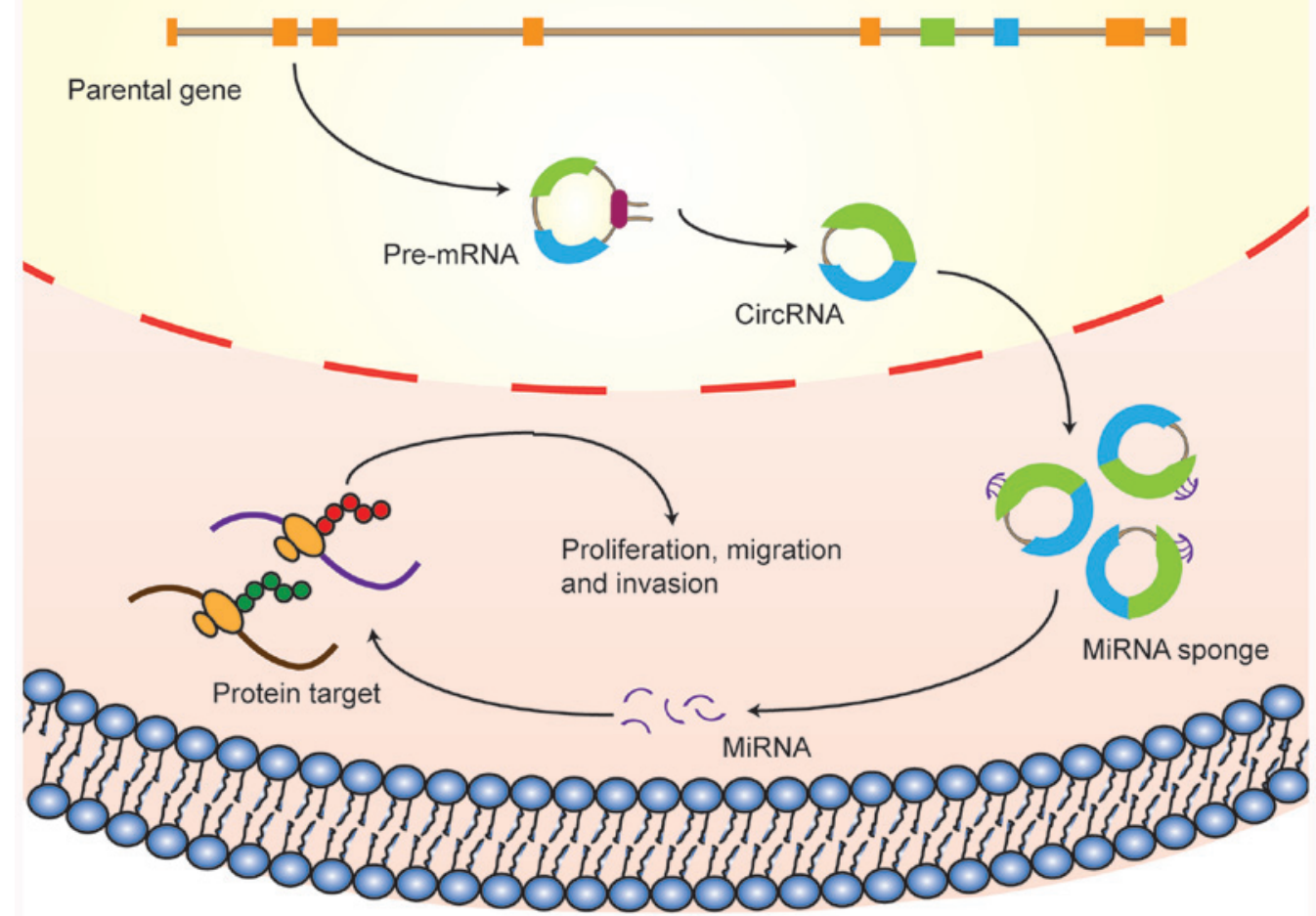

Figure 2. CircRNA serves as a miRNA sponge in tumors of the digestive system. After the parental gene is spliced into a loop through a complex process in the nucleus, the mature circRNA enters the cytoplasm and sequesters miRNAs, reducing their downstream effects, in turn regulating the expression of downstream target proteins and affecting tumor proliferation, invasion and migration. CircRNA, circular RNA; miRNA, microRNA. 
digestive system malignancies. By sponging miRNA, circRNA can regulate the expression of target proteins, in turn affecting the pathophysiology of tumors of the digestive system (Fig. 2). This section describes the differential expression profiles and reported functions of circRNA in various types of digestive system malignancies.

Esophageal and gastric cancer. Esophageal cancer is a tumor of the upper digestive tract, which ranks 7th and 6th in terms morbidity and mortality among all cancers, respectively (10). By contrast, gastric cancer ranks 5th and 3rd in terms of morbidity and mortality among all cancers, respectively (8). Although a number of advancements have been made in the diagnosis and treatment of esophageal and gastric cancer in recent years, the etiology of these two malignancies remain to be fully elucidated and the survival rates of patients with advanced disease remain poor. The lack of effective early diagnostic indicators is also an important cause for the high mortality rates observed in patients with these two types of malignancies. Accumulating evidence have shown that circRNA serves a pivotal role in the proliferation, invasion, migration, cell cycle progression and drug resistance of esophageal (Table I) and gastric cancers (Table II).

Since 2016, the number of studies on the relationship between circRNAs and esophageal cancer has increased gradually. The elevated expression levels of several circRNAs in esophageal cancer has been demonstrated to promote the proliferation of esophageal cancer cells, including circ-discs large homolog 1, circRNA_100876 and hsa_circ_0067934 (32-34). In addition to proliferation, aberrant circRNA expression has also been reported to influence the ability of cancer cells to invade and migrate, which is a crucial cause of tumor metastasis and subsequent mortality. Zhong et al (35) found that circ-plasmacytoma variant translocation (circ-PVT1) upregulated the expression of paired box proteins and peroxisome proliferator-activated receptors by sponging miR-4663, resulting in the promotion of esophageal cancer cell proliferation and migration. The elevated expression levels of circ-tetratricopeptide repeat domain 17, circ-fibronectin type III domain containing 3B (circFNDC3B) and hsa_circ_0000337 have also been revealed to be involved in the proliferation and migration of esophageal cancer cells (36-38). Hsa_circ_0006168, circ-protein kinase $\mathrm{Cl}$ (circ-PRKCI), c-zinc finger protein 292 (cZNF292), circRAD23B, circ-ubiquitin associated protein 2 (circUBAP2) and hsa_circ_0004370 were all found to be upregulated in esophageal cancer cells and tissues, where they have the reported function of promoting proliferation, invasion and migration (39-44). Mechanistically, hsa_circ_0006168, circ-PRKCI, cZNF292, circRAD23B regulate the $\mathrm{PI} 3 \mathrm{~K} / \mathrm{AKT} / \mathrm{mTOR}$ signaling pathway by sponging miR-100, miR-3680-3p, miR-206 and miR-5095, respectively; whilst circUBAP2 and hsa_circ_0004370 regulate Rab10 and LIM And SH3 protein 1 by sponging miRNA-422a and miR-1294, respectively (39-44). miR-7 is a widely studied miRNA, the expression of which has been previously found to be reduced as a result of competition from ciRS7 in esophageal cancer, leading to the activation of NF- $\mathrm{KB}$ signaling, causing changes to the immune microenvironment to potentiate tumorigenesis (45). In addition to

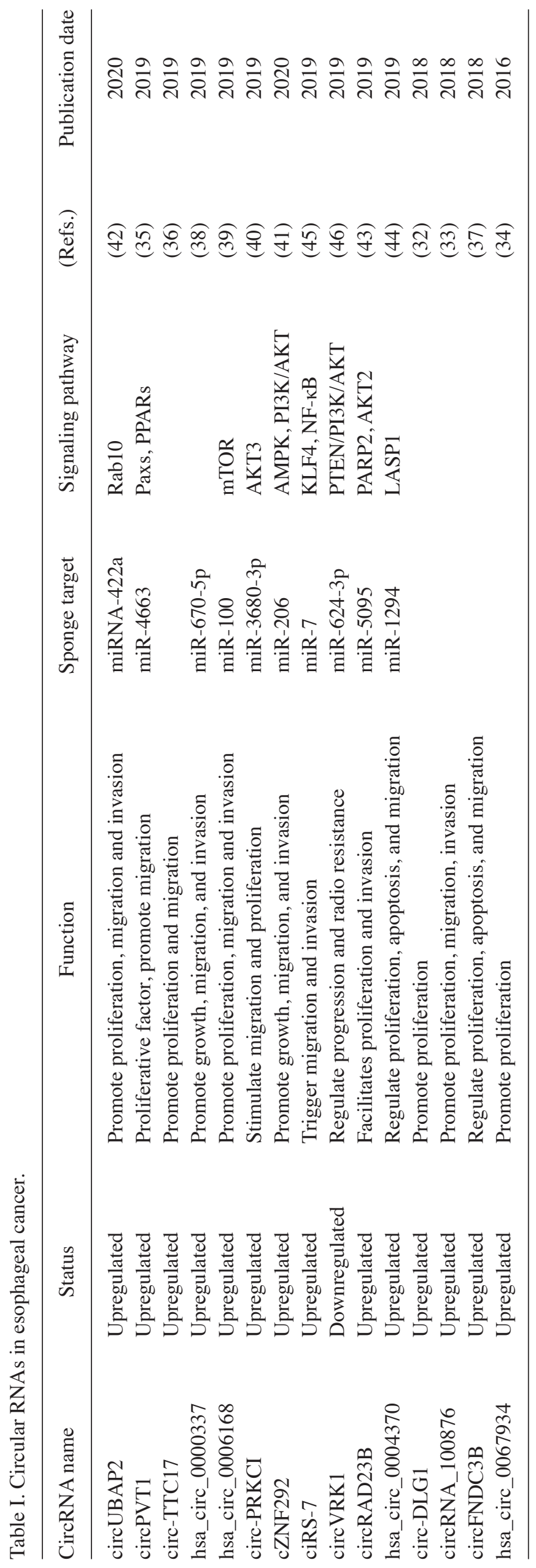




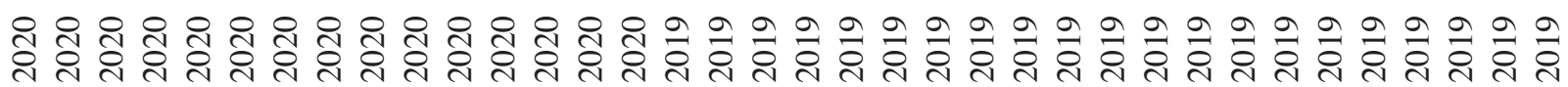

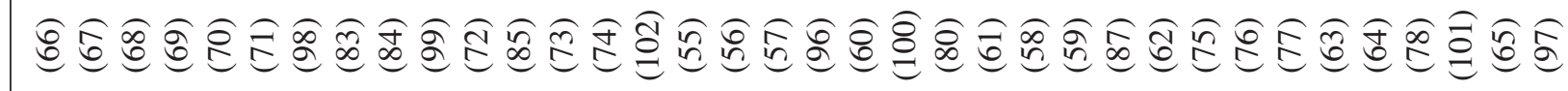

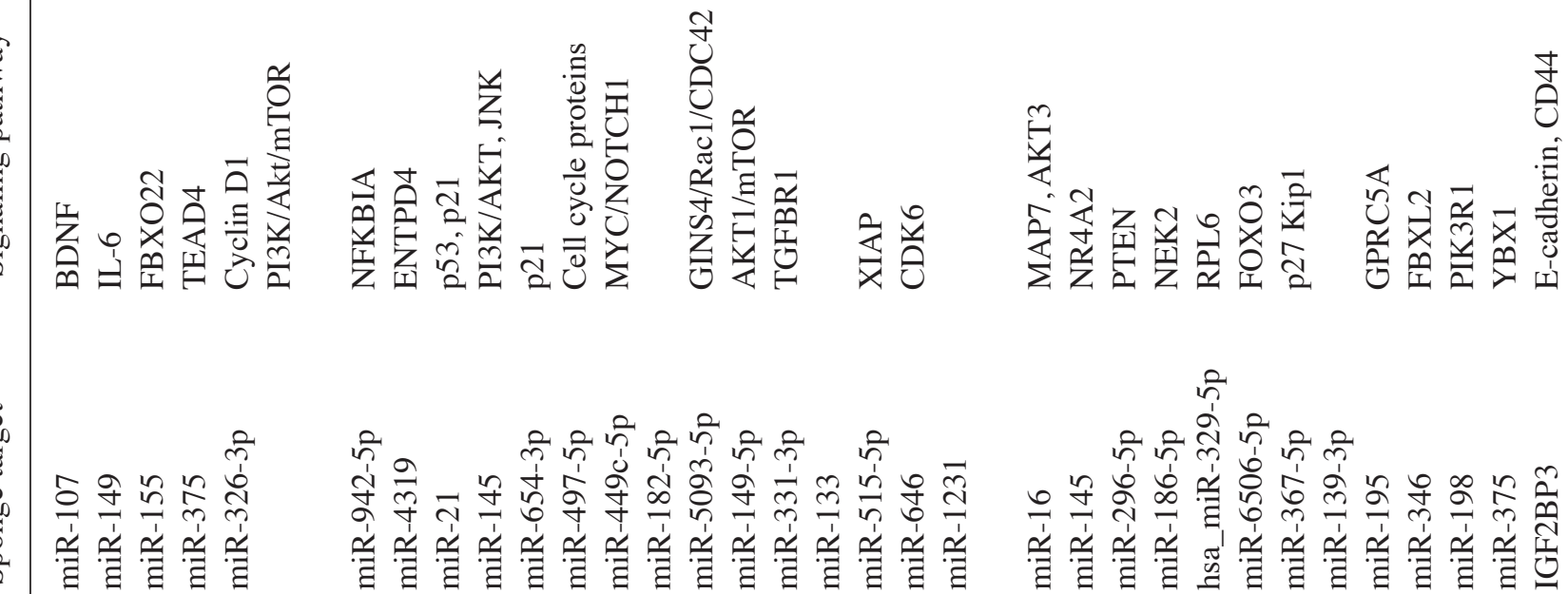

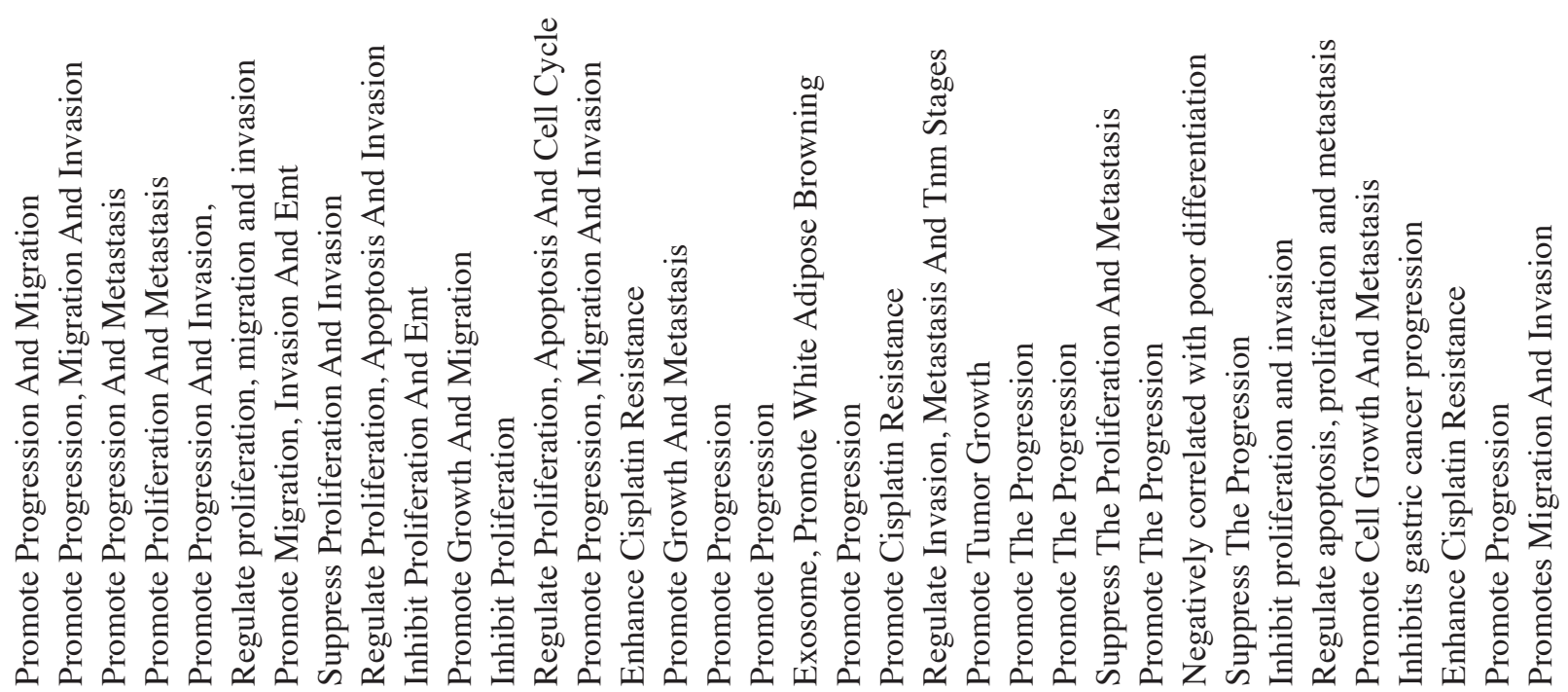




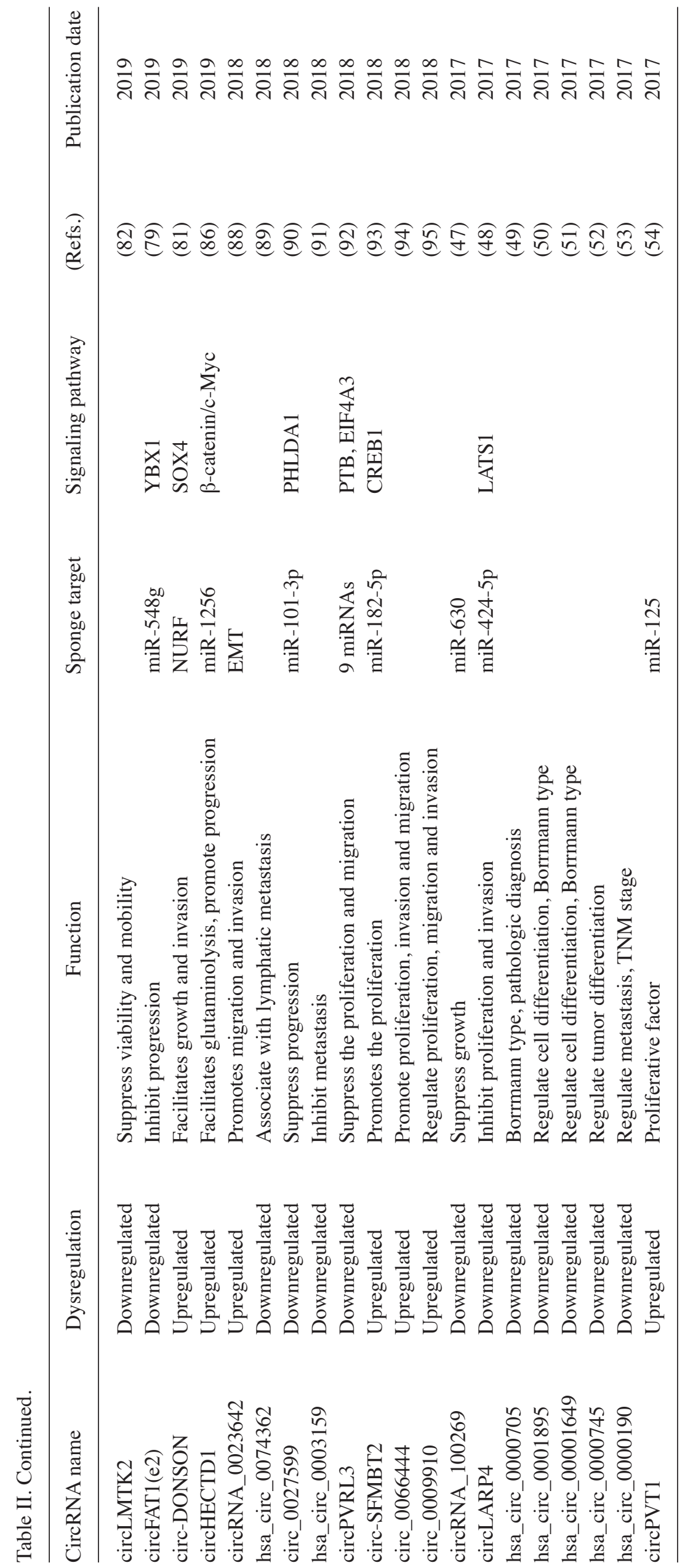


proliferation, invasion and migration, evidence also exists demonstrating the role of circRNA in tumor sensitivity to radiotherapy. He et al (46) previously found that the downregulation of circ-vaccinia-related kinase 1 (circVRK1) in patients with esophageal cancer was associated with a lower survival rates, whilst the overexpression of circVRK1 could effectively inhibit EMT and resistance to radiotherapy in esophageal cancer cells.

Similar to esophageal cancer, research on the association between circRNA and gastric cancer has been gradually increasing since 2017. In 2017, studies discovered that circRNA_100269, circRNA_La ribonucleoprotein 4, hsa_circ_0000705, hsa_circ_0001895, hsa_circ_00001649, hsa_circ_0000745 and hsa_circ_0000190 are all significantly downregulated in gastric cancer, which were found to be closely associated with the increased cell proliferation, differentiation, subcellular localization, stage, Borrmann type and invasion (47-53). By contrast, circ-PVT1 was demonstrated to serve as a proliferative factor regulating downstream gene expression by sponging miR-125 in gastric cancer (54). miRNA sponging remains to be the predominant mechanism through which circRNA promotes the proliferation, invasion and migration of gastric cancer cells. By sponging miR-509-3-5p, circ-myeloid/lymphoid or mixed-lineage leukemia has been found to be regulated by the expression of GINS4, which binds to and activates Rac1/cell division cycle to promote cell growth and metastasis in vivo and in vitro, whilst inhibiting apoptosis (55). Circ-nuclear receptor interacting protein 1, circ-cactin, circ-neurofibromatosis type 1 along with 37 other circRNAs have been previously revealed to regulate the expression of downstream target genes in gastric cancer through miRNA sponging to promote the proliferation and invasion of gastric cancer (Table II) (56-95). Disorder in fat metabolism is the main cause of cachexia in patients with advanced gastric cancer and systemic inflammation (96). CiRS-133 is a plasma exosomal circRNA that has been found to be significantly upregulated in gastric cancer (96). Zhang et al (96) found that it can activate PR/SET domain 16 by inhibiting miR-133, causing the browning of white adipose tissues in patients with gastric cancer. Other circRNAs can also affect the invasion and metastasis of gastric cancer by regulating EMT. The increased expression of circFNDC3B and the reduced expression of circSMAD7 and circ-hippocampus abundant transcript 1 (circHIAT1) in gastric cancer has been found to promote EMT in gastric cancer and induce distant metastasis, which is the primary cause of poor prognosis in patients with advanced gastric cancer (97-99). Hsa_circ_0081143 is another circRNA that is highly expressed in gastric cancer, which is positively associated with lymph node metastasis and TNM staging in advanced gastric cancer (100), the silencing of which can inhibit the development of gastric cancer and enhance the sensitivity of gastric cancer cells to chemotherapeutic agents such as cisplatin (100). Similarly, circAKT3 and circ-fibronectin 1 were found to enhance cisplatin resistance by sponging miR-198 and miR-182-5p, respectively $(101,102)$.

Pancreatic cancer. Pancreatic cancer is a common tumor of the digestive system. Although the rates of morbidity associated with pancreatic cancer is not as high as other types of digestive system malignancies, including gastric, esophageal, colorectal and hepatocellular cancers, its mortality rate ranks among the highest (8). Pancreatic cancer is mainly divided into two subtypes: Pancreatic ductal adenocarcinoma and pancreatic squamous cell carcinoma, both of which have a poor prognosis, with a 5-year survival rate of $<10 \%$ (103). Identifying specific biomarkers and therapeutic targets is important for improving the survival rates of patients with pancreatic cancer.

Interestingly, the majority of circRNAs associated with pancreatic cancer that have been discovered are found to be upregulated (Table III).CircRNAs, including hsa_circRNA_0007334, circ-Ras homolog family member T1, hsa_circ_0006215, circ-zinc finger MYM-type containing 2, circ-disintegrin and metalloproteinase domain-containing protein (ADAM) 9 and ciRS-7, compete with miRNAs to promote pancreatic cancer proliferation and inhibit apoptosis (104-109). Other circRNAs can regulate endothelial monolayer permeability, thereby promoting the invasion and migration of pancreatic cancer cells. Circ-low density lipoprotein receptor class a domain containing 3 promotes lymphatic and venous metastasis by sponging miR-137-3p, whilst circ-isoleucyl-tRNA synthetase enhances endothelial monolayer permeability by sponging miR-122 $(110,111)$. Abnormalities in the immune microenvironment are common changes observed in advanced pancreatic cancer. Circ_0000977 has been previously found to increase the expression of hypoxia-inducible factor 1 and ADAM10 by competitively binding to miR-153, where circ_0000977 silencing can significantly enhance the cytotoxic effects of natural killer cells on pancreatic cancer (112). Drug resistance is another important underlying cause of poor prognosis in patients with advanced pancreatic cancer. Liu et al (113) previously found that knocking down circ-homeodomain interacting protein kinase 3 expression can effectively improve the sensitivity of pancreatic cancer to gemcitabine. In general, there have been a number of studies on the relationship between pancreatic cancer and circRNA, where the role of circRNA in the development of pancreatic cancer require further exploration.

Hepatocellular carcinoma. As of 2018, liver cancer ranks 6th in terms of prevalence and 4th in terms of mortality rates among other cancers (8). Liver cancer can be divided into three main subtypes: Hepatocellular carcinoma, bile duct carcinoma and mixed carcinoma by cell type, of which hepatocellular carcinoma is the most frequently observed. Viral hepatitis B (HBV) is one of the main causes of liver cancer in China whereas alcoholic fatty liver disease is the main cause in the Western world (114). Hepatocellular carcinoma as a result of both HBV infection and excessive alcohol consumption are associated with high rates of morbidity and mortality (8). Due to the lack of symptoms in the early developmental stage of hepatocellular carcinoma, many are not diagnosed until advanced stages of the disease (115). Studying the molecular mechanism of circRNA in hepatocellular carcinoma is of great importance for the early diagnosis and treatment of this disease.

In 2016, Yu et al (116) found that circ-cerebellar degeneration related protein 1; antisense served as a cancer promotor by binding to miR-7 and upregulating the expression of cyclin E1 and phosphatidylinositol-4,5-bisphosphate 3-kinase catalytic subunit $\mathrm{d}$, promoting the proliferation and metastasis of hepatocellular carcinoma. Studies into the role of circRNA in hepatocellular carcinoma has since increased annually. A total of four studies 


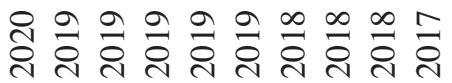

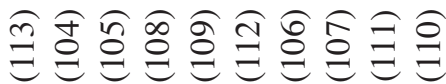

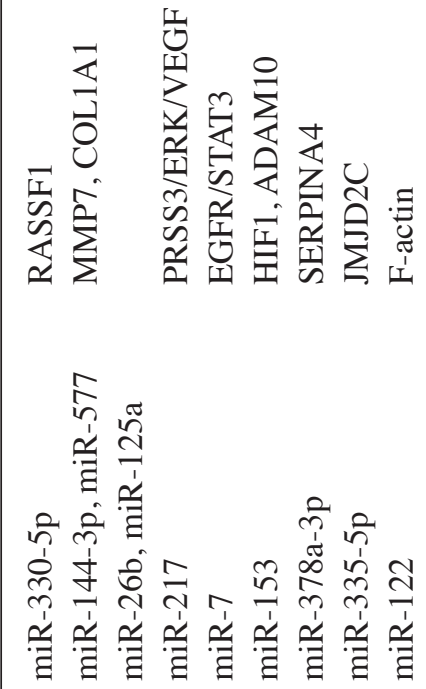

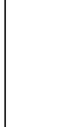

were published the following year, which reported that circRNA serves as an endogenous competitor by regulating the expression of downstream target genes by sponging miRNA to promote hepatocellular carcinoma proliferation, invasion, migration and differentiation, whilst inhibiting apoptosis. This suggests that circRNA can be applied as a biomarker for hepatocellular carcinoma (Table IV) (117-120). The number of studies on circRNA in relation to hepatocellular carcinoma increased to 16 in 2018, where it was revealed that in addition to sponging miRNA, circRNA can also participate in the progression of hepatocellular carcinoma by directly binding to proteins to regulate their function (Table IV) (121-136). For example, circ-cullin 2 was previously demonstrated to promote epithelial-mesenchymal transition by combining vimentin under the regulation of Twist 1 in hepatocellular carcinoma (130).

The association between circRNA and cancer, especially that of hepatocellular carcinoma, has become a popular topic of research over the last 2 years. In early 2020, a total of 56 related research articles reporting the relationship between circRNA and hepatocellular carcinoma have been published, which is higher than the number recorded in previous years (Table IV) (137-192). The expression of several circRNAs has been reported to be dysregulated in hepatocellular carcinoma, which compete with miRNAs to regulate the expression of downstream target proteins and affect the proliferation, invasion and migration of hepatocellular carcinoma. Some of these circRNAs include hsa_circ_0101432, circ-PVT1, circ-tripartite motif containing 33-12, circRNA-104718, circ-SET domain containing 3, actin histidine methyltransferase, has_circ_0078710, hsa_circ_0064428, circHIAT1, circ-adducin3, hsa_circ_0001649, circ-ADAM metallopeptidase with thrombospondin type 1 motif 14, circ_0008450, hsa_circRNA_103809, circ-homer scaffold protein 1, hsa_circ_0003645, circ-SMG1.72, hsa_circ_0091581, hsa_ circ_0000092, hsa_circ_0056836, circ-TCF4.85, circ-protein arginine methyltransferase 5 (circPRMT5), circ_0001955, circ-pecanex 1, circRNA-5692, circ-ATP binding cassette subfamily B member 10 and circ-ArfGAP with SH3 domain, ankyrin repeat and PH Domain $1(137,138,140,145,147-150$, 155-157,163,166,176-180,183-185,187,189-192). Previous studies have demonstrated that circRNA in exosomes can regulate the development of hepatocellular carcinoma by deubiquitylation. Circ-leptin receptor, circ-matrix metallopeptidase 2 and hsa_circ_0051443 are common exosomal circRNAs found in hepatocellular carcinoma $(142,181,186)$. Hypoxia is a principal characteristic of the tumor microenvironment that is considered to be an important factor affecting sensitivity to radiotherapy and chemotherapy (146). Yang et al (146) previously found that knocking down cZNF292 expression can inhibit angiogenesis, cell proliferation and resistance to radiotherapy in hepatocellular carcinoma, which may be due to the hypoxic environment induced by cZNF292. Similar to cZNF292, the dysregulation of circRNA_101505, circRNA_104797 and circ_0003418 expression in hepatocellular carcinoma has been demonstrated to increase the resistance of hepatocytes to sorafenib and cisplatin, which is considered to be one of the main underlying causes of poor prognosis in patients with advanced hepatocellular carcinoma $(162,168,174)$. CircRNA can also directly bind to protein components of important signaling pathways, thereby affecting the physiological behavior of hepatocellular carcinoma. The 


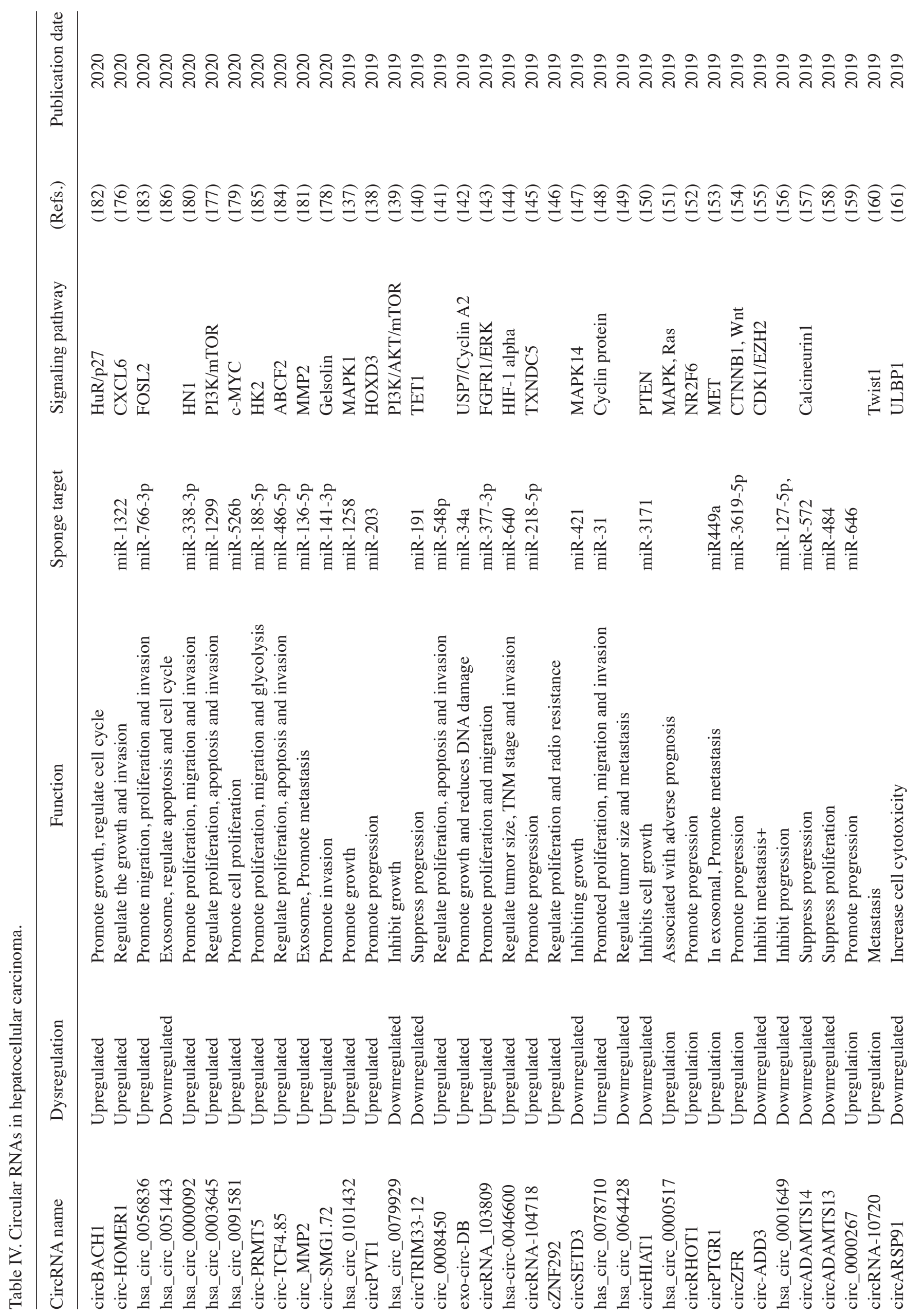




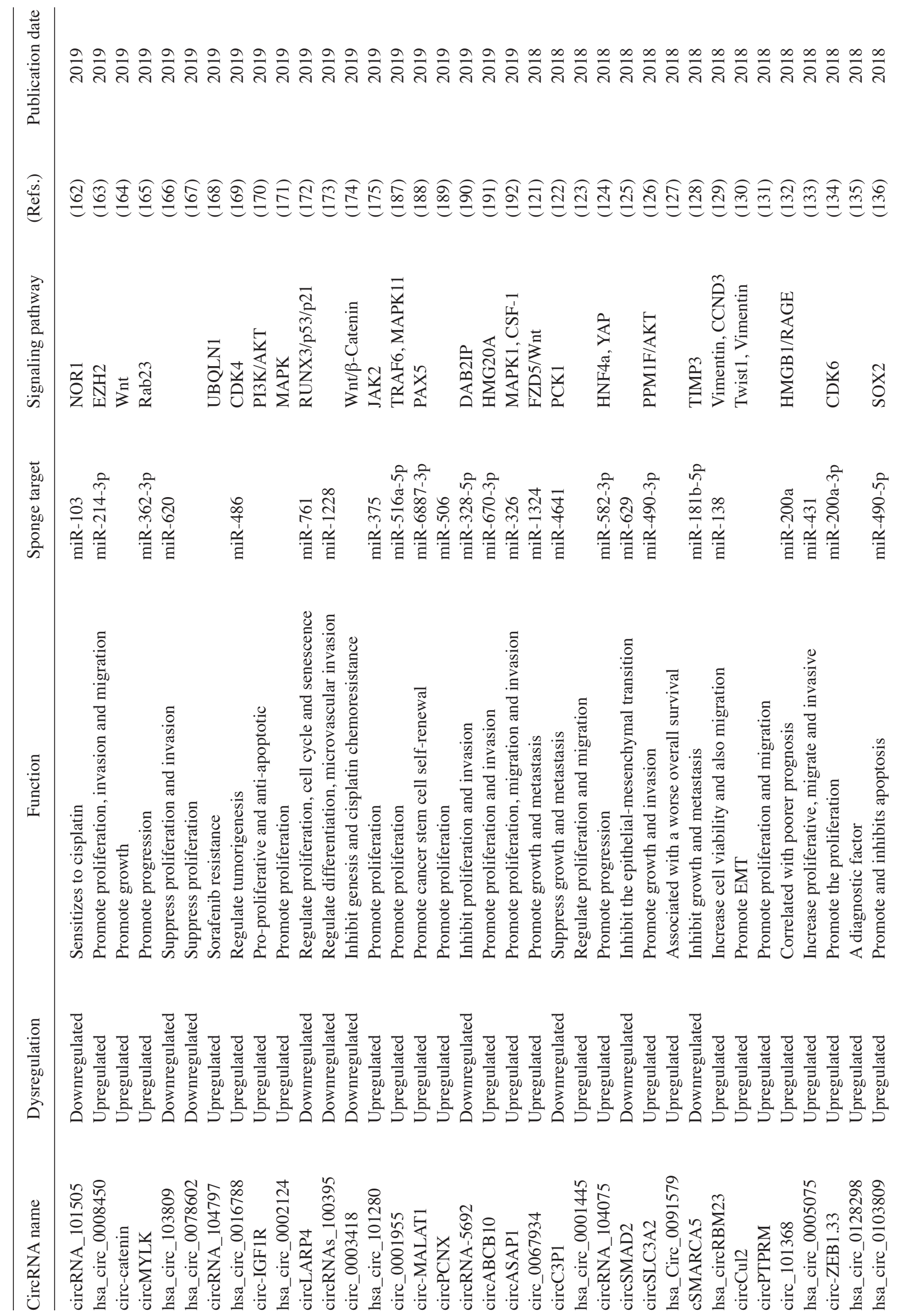



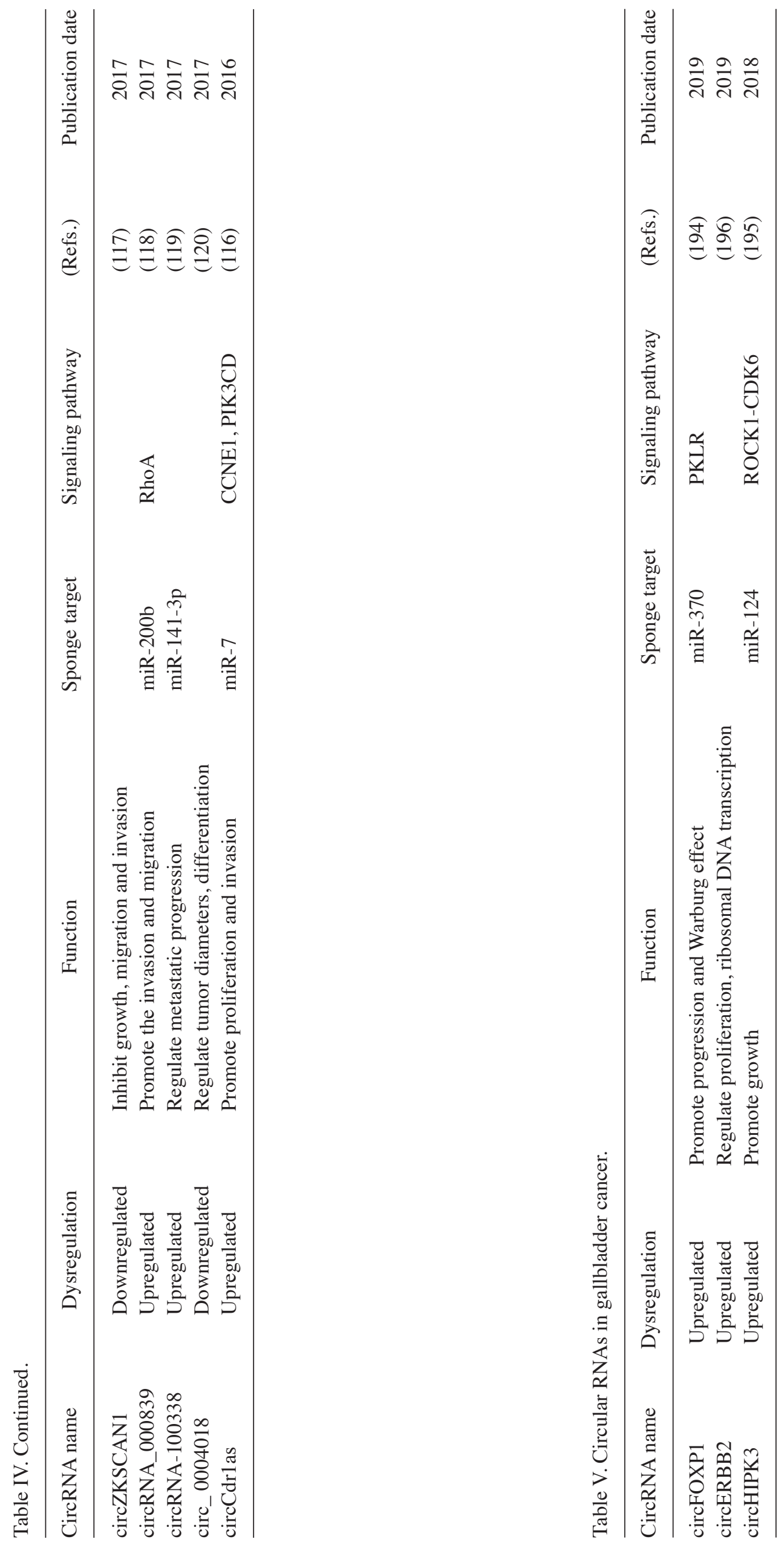
expression of hsa_circ_0079929 and circ-insulin-like growth factor 1 receptor in hepatocellular carcinoma was demonstrated to be significantly reduced, which induced cell cycle arrest and inhibited apoptosis through the PI3K/AKT/mTOR signal transduction pathway $(139,170)$. Circ-BTB domain and CNC homolog 1 was found to be highly expressed in hepatocellular carcinoma, which binds to the embryonic lethal, abnormal vision, drosophila, homolog-like 1 protein and p27 to regulate cell cycle progression and promotes the growth of tumor cells (182). Ma et al (161) previously found that circARSP91 enhance innate immune monitoring by enhancing NK cell cytotoxicity and its downregulation in hepatocellular carcinoma promotes immune escape of hepatocellular cancer cells.

In conclusion, circRNA serves a significant role in proliferation, invasion, migration, differentiation, apoptosis, cell cycle and sensitivity to chemotherapy in hepatocellular carcinoma. Future research should focus on identifying specific and sensitive circRNAs that can serve as biomarkers for the early diagnosis and effective treatment of hepatocellular carcinoma, to improve the survival rate of patients with hepatocellular carcinoma.

Gallbladder cancer. Compared with hepatocellular carcinoma, although the rates of morbidity associated with gallbladder cancer is not as high, the rates of mortality are high where its prognosis poor, due to the highly invasive properties which is frequently diagnosed during the advanced stages of the disease (193). Studies have found that circRNA promotes the proliferation of gallbladder cancer cells through miRNA sponging and direct binding to proteins. As a miRNA sponge, circ-forkhead box protein $\mathrm{P} 1$ regulates the expression of pyruvate kinase L/R by sponging miR-370, enhancing the Warburg effect and promoting the proliferation and invasion of gallbladder cancer cells (194). In addition, circ-homeodomain interacting protein kinase 3 has been previously found to increase the expression of Rho-associated coiled-coil containing protein kinase 1-CDK6 by sponging miR-124, promoting the proliferation of gallbladder cancer cells (195). Circ-Erb-B2 binds to the circErb-B2 receptor tyrosine kinase 2 located in the nucleus, which regulates proliferation-associated 2G4-dependent ribosomal DNA transcription and promotes the proliferation of gallbladder cancer (196). In conclusion, research on the mechanism of circRNA involvement in the occurrence and development of gallbladder cancer remains limited (Table V) and several important issues have yet to be explained. Therefore, there remains room for exploration in this particular field.

Colorectal cancer. Colorectal cancer ranks 3rd and 2nd worldwide in terms of morbidity and mortality, respectively, among other types of cancers. (8). Advancements in colonoscopy have facilitated the detection and treatment of precancerous colorectal polyps. However, the mortality and risk associated with colorectal cancer have changed little since 1997 (197). At present, there is an urgent need in identifying novel tumor biomarkers and targeted treatment strategies to improve the early diagnosis and survival rate of patients with colorectal cancer.

Studies into the relationship between colorectal cancer and circRNA preceded those of other digestive system malignancies. In 2015, a study on 31 clinical samples of colorectal cancer found that the elevated expression of hsa_circ_001988 in colorectal cancer is closely associated with the differ- entiation and infiltration of tumor cells (198). In 2016, circRNA_001569 and hsa_circ_0000069 were found to be highly expressed in patients with colorectal cancer $(199,200)$. CircRNA_001569 was demonstrated to regulate the expression of Bcl-2-associated athanogene 4, transcription factor E2F5 and formin like 2 by adsorbing miR-145, though the mechanism mediated by hsa_circ_0000069 remain unknown $(199,200)$. In 2017, it was found that the expression of circRNA0003906, circ-BTG3-associated nuclear protein and hsa_circ_0020397 were dysregulated in colorectal cancer (201-203). A total of 10 studies reporting that circRNA regulated the development of colorectal cancer were published in 2018 (Table VI) (204-213), which rose to 17 in 2019 and 9 related articles have already been published in the first 2 months of 2020 (Table VI) (214-239). Over the last 5 years, the number of studies into the role of circRNA in colorectal cancer has been increasing annually. Most aberrantly expressed circRNAs in colorectal cancer exert their function by adsorbing miRNAs, regulating proteins associated with proliferation, invasion and metastasis, thereby promoting the progression of colorectal cancer. Particular circRNAs of interest include hsa_circ_0136666, circCBL.11, hsa_circRNA_102958, circ-vesicle-associated membrane protein-associated protein A, circ-formin 2, circ_0021977, circ_0026344, circ-integrin subunit- $\alpha 7$, has_circ_0055625, circ-calmodulin regulated spectrin associated protein 1, hsa_circ_0007142, circ-HECT, UBA and WWE domain containing E3 ubiquitin protein ligase 1, circ-chaperonin containing TCP1 subunit 3, circ_0000218, hsa_circ_0001178, circPRMT5 and hsa_circ_0004277 (215$220,223,226,227,229-234,236,238)$. CircRNAs have been reported to serve either a synergistic or antagonistic role by directly binding to downstream target proteins to regulate various aspects of colorectal cancer pathophysiology. Circ-catenin b1 (circ-CTNNB1) mainly exists in the nucleus and directly binds to DEAD-box helicase 3/yin and yang 1, resulting in b-catenin activation and promoting the growth and metastasis of colorectal cancer (225). CircRNA_104916, circ-zinc finger protein 609 and circ-protein tyrosine kinase 2 have been previously demonstrated to function in a similar manner to circ-CTNNB1 $(221,228,237)$. Exosome circRNA has been a topic of particular research interest in recent years, as it is believed that circRNA may regulate tumor development. Using nanoparticle tracking analysis and transmission electron microscopy, Pan et al (222) verified the exosomes in the peripheral blood of patients with colorectal cancer. Hsa_circ_0004771, ciRS-122 and circ-ATP binding cassette subfamily C Member 1 were found to be significantly increased in these exosomes, suggesting their possible application as a suitable biomarker for this disease $(222,235,239)$.

Gastrointestinal stromal tumor. A gastrointestinal stromal tumor is a non-epithelial type of tumor that can occur in the esophagus, stomach, small intestine, colorectum and abdominal cavity that can cause a variety of symptoms, including pain, bleeding and abdominal discomfort (240). Surgical resection is currently the most common treatment method (240). In a recent study, Jia et al (241) used a selective binding complementary competitive endogenous RNA array to analyze gastrointestinal stromal tumors, which found circ_0084097, circ_0069765 and circ_0079471 to be aberrantly expressed in gastrointestinal 


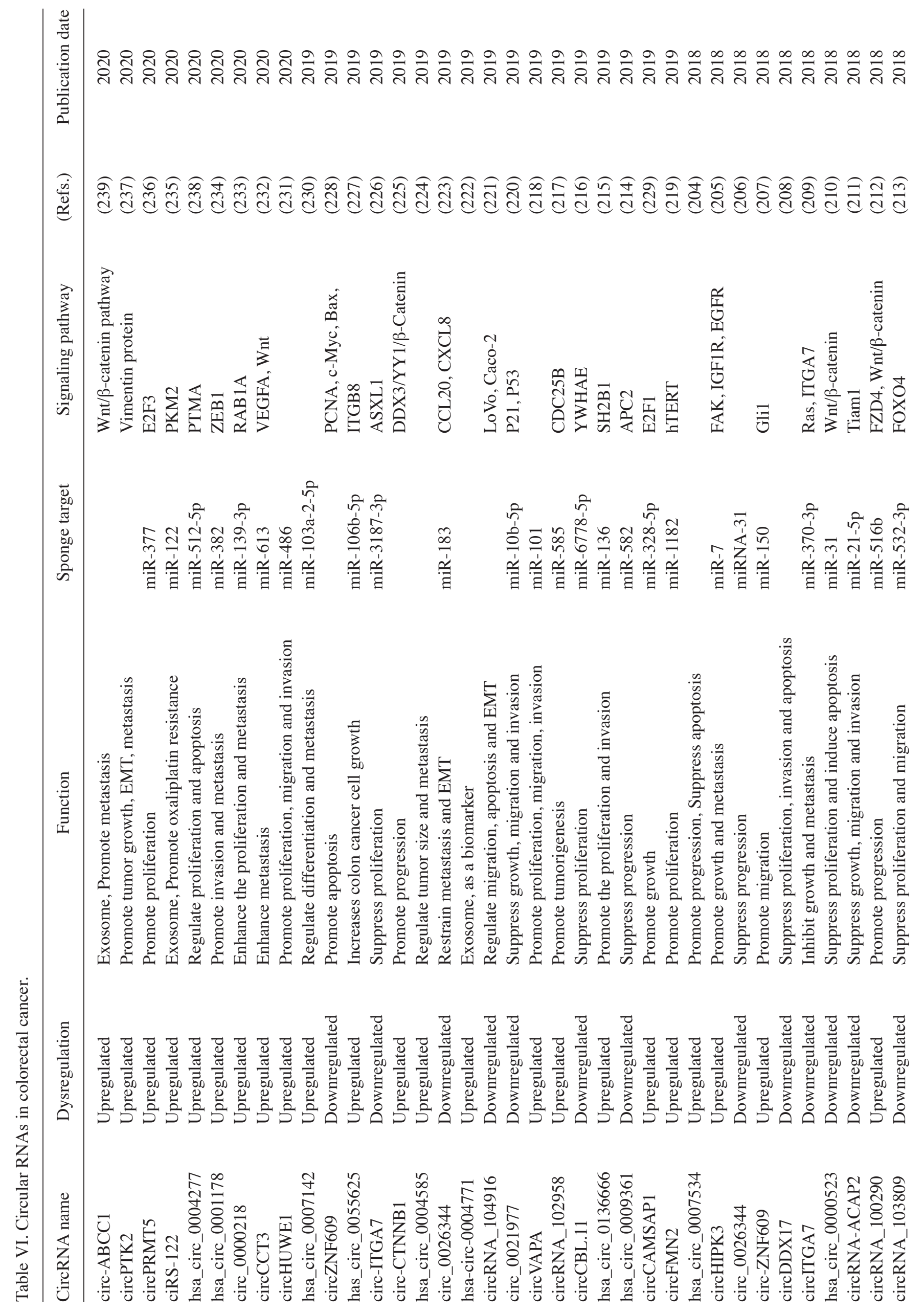




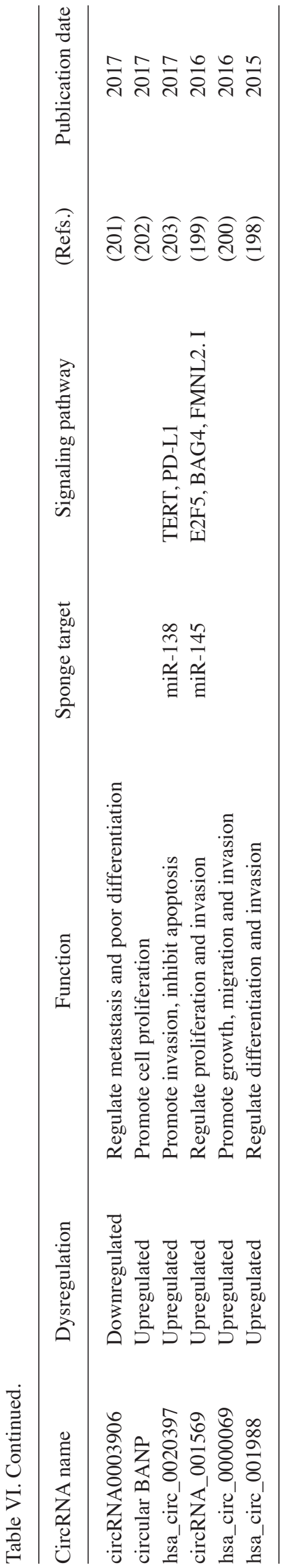

stromal tumors. Although further study suggested these circRNAs to serve a regulatory role by sponging mir-144-3p, mir-142-5-p and mir-485-3p (241), there is no experimental data on the mechanism of circRNA involved in the development of gastrointestinal stromal tumors. It remains unclear if circRNA can be applied as a biomarker and therapeutic target for the diagnosis of gastrointestinal stromal tumors at present.

\section{Non-coding RNAs in digestive system malignancies}

Non-coding RNA is comprised of a large family of different subtypes of RNA molecules. In addition to circRNA, it also includes miRNA, long non-coding RNA (lncRNA), piwi-interacting RNA, transfer RNA, ribosomal RNA and small interfering RNA. Over the past decade, numerous studies have demonstrated that non-coding RNAs can exert regulatory effects. They serve an irreplaceable role in transcription, post-transcriptional modification, protein remodeling and cell signal transduction (242). Supporting this, non-coding RNA dysfunction has been documented to be associated with the occurrence and progression of various chronic diseases and tumors (242).

miRNA is a family of single-stranded, non-coding RNA that are typically 21-25 nucleotides in length and negatively regulates $>60 \%$ of coding genes (243). Most miRNAs contain a 2-7 nucleotide seed sequence at the 3'untranslated region (3'-UTR) end, which can conservatively bind to a variety of target protein-coding genes to inhibit target mRNA translation (243). The function of miRNA itself is under negative regulation by circRNA- or lncRNA-mediated sponging (243). In a previous study, miR-7 was found to inhibit osteosarcoma cell proliferation and migration, but circRNA-CDRlas promotes osteosarcoma growth by sponging miR-7 (244) Similar cancer-promoting effects as a result of reduced miR-7 expression have also been reported in gastric cancer, colorectal cancer, pancreatic cancer and hepatocellular carcinoma $(109,206,245,246)$. However, it should be noted that not all miRNAs have a seed sequence at the 3'UTR end. In addition to directly inhibiting mRNA translation, a number of miRNAs can also participate in pre-transcriptional regulation by binding to the argonaute- 2 protein in the nucleus (247). However, this phenomenon is yet to be observed in tumors of digestive system.

LncRNA is a type of non-coding RNA that are $>200$ nucleotides in length, which has been previously shown to serve a significant role in maintaining the tumor microenvironment and the progression of various digestive system malignancies (248). Similar to circRNA, many lncRNAs also have the ability to sponge miRNAs. Yuan et al (248) found that the IncRNA SWI/SNF related, matrix associated, actin dependent regulator of chromatin subfamily $\mathrm{C}$ member 2 upregulates transmembrane serine protease 2 by binding to miR-551b-3p, promoting the proliferation and invasion of gastric cancer. LncRNA can also directly interact with double-stranded RNA to regulate the activity of some proteins (249). A previous study has found that LINC00665 can activate and enhance the expression of protein kinase $\mathrm{R}$ by protecting it from ubiquitin-dependent degradation, in turn upregulating the NF- $\mathrm{kB}$ signaling pathway and the widespread expression of inflammatory factors, resulting in changes to the microenvironment and the occurrence of hepatocellular carcinoma (249). 
In short, non-coding RNA forms a complex network of interactions in the body. where dysfunctions in any one of the nodes will significantly impact the entire non-coding RNA network, resulting in the development of diseases. The occurrence and procession of digestive system malignancies are closely associated with the aberrant expression of these non-coding RNAs. CircRNA is an important part of the non-coding RNA family, where its function in tumors has garnered attention in recent years. The present study reviewed the research status of circRNA in seven types of tumors in the digestive system, where the potential mechanism underlying circRNA function in their respective malignancies were discussed in detail and the possibility of using circRNA as a diagnostic and prognostic marker for tumors in the digestive system was demonstrated. However, this article is associated with limitations, since it did not discuss in detail the role of circRNAs in cellular and signal transduction pathways. CircRNA has a complex intracellular mechanism of action, which is regulated by a variety of transcriptional regulatory factors and can also affect downstream biological functions by direct interaction with miRNAs and proteins. In addition, circRNA can exert biological functions in the nucleus, cytoplasm or through exosomes secreted into bodily fluids. The associated in-depth mechanism in digestive system malignancies remain to be fully elucidated and require further investigation in future studies.

\section{Conclusions and perspectives}

The present review briefly explored the biogenesis and function of circRNA and reviewed in detail the current status of circRNA research in various types of digestive system malignancies. CircRNA is a class of endogenous non-coding RNA that is evolutionarily conserved, the expression of which was found to be dysregulated in a variety of digestive system tumors. In digestive system malignancies, the majority of circRNAs serve an endogenous competitive role through miRNA sponging, whilst a selective number of circRNAs can directly bind to proteins either as sponges or synergistic factors to regulate tumor growth, invasion and migration, in turn influencing patient prognosis. Compared with traditional linear RNA and other families of RNA molecules, including long-chain non-coding RNA and miRNA, circRNA is widely expressed in various tissues, cells and bodily fluids, where its expression is stable, increasing their potential as biomarkers and targets for therapy. With continuous advancements in experimental technology and continuing research, it is hoped that novel functions and modes of action mediated by circRNA will be discovered and clarified in the future. With the joint efforts of researchers and clinicians, the pathogenesis of various malignant tumors of the digestive system will be elucidated, so that patients will have an increased chance of survival.

\section{Acknowledgements}

Not applicable.

\section{Funding}

The present study was supported by the National Natural Science Foundation of China (grant nos. 71964021 and
81570783), National Key R\&D Program of China (grant nos. 2016YFC1302201 and 2016YFC0107006), Key Research and Development Program of Gansu Province (grant no. 18YF1FA110), the Key Program of the Natural Science Foundation of Gansu Province (grant no. 18JR3RA366), the Foundation of The First Hospital of Lanzhou University (grant no. ldyyyn2018-54), the Open Fund of State Key Laboratory of Cancer Biology (grant no. CBSKL201718).

\section{Availability of data and materials}

All data analyzed during this review are included in this published article.

\section{Authors' Contributions}

HW, YW, and XZ consulted and analyzed the literature, produced the figures and wrote the manuscript. YZ and QG were responsible for reviewing and correcting the manuscript. RJ and $\mathrm{YZ}$ proposed and built the theoretical framework of the article. All authors read and approved the final version of this manuscript.

\section{Ethics approval and consent to participate}

Not applicable.

\section{Patient consent for publication}

Not applicable.

\section{Competing interests}

The authors declare that they have no competing interests.

\section{References}

1. Liu CX, Li X, Nan F, Jiang S, Gao X, Guo SK, Xue W, Cui Y, Dong K, Ding H, et al: Structure and degradation of circular RNAs regulate PKR activation in innate immunity. Cell 177: 865-880.e21, 2019.

2. Sanger HL, Klotz G, Riesner D, Gross HJ and Kleinschmidt AK: Viroids are single-stranded covalently closed circular RNA molecules existing as highly base-paired rod-like structures. Proc Natl Acad Sci USA 73: 3852-3856, 1976.

3. Hansen TB, Kjems J and Damgaard CK: Circular RNA and miR-7 in cancer. Cancer Res 73: 5609-5612, 2013.

4. Memczak S, Jens M, Elefsinioti A, Torti F, Krueger J, Rybak A, Maier L, Mackowiak SD, Gregersen LH, Munschauer M, et al: Circular RNAs are a large class of animal RNAs with regulatory potency. Nature 495: 333-338, 2013.

5. Zhu K, Hu X, Chen H, Li F, Yin N, Liu AL, Shan K, Qin YW, Huang X, Chang Q, et al: Downregulation of circRNA DMNT3B contributes to diabetic retinal vascular dysfunction through targeting miR-20b-5p and BAMBI. EbioMedicine 49: 341-353, 2019.

6. Chen Y, Li Z, Zhang M, Wang B, Ye J, Zhang Y, Tang D, Ma D, Jin W, Li X and Wang S: Circ-ASH2L promotes tumor progression by sponging miR-34a to regulate Notch1 in pancreatic ductal adenocarcinoma. J Exp Clin Cancer Res 38: 466, 2019.

7. Zuo L, Zhang L, Zu J, Wang Z, Han B, Chen B, Cheng M, Ju M, Li M, Shu G, et al: Circulating circular RNAs as biomarkers for the diagnosis and prediction of outcomes in acute ischemic stroke. Stroke 51: 319-323, 2020.

8. Bray F, Ferlay J, Soerjomataram I, Siegel RL, Torre LA and Jemal A: Global cancer statistics 2018: GLOBOCAN estimates of incidence and mortality worldwide for 36 cancers in 185 countries. CA Cancer J Clin 68: 394-424, 2018. 
9. Jeck WR, Sorrentino JA, Wang K, Slevin MK, Burd CE, Liu J, Marzluff WF and Sharpless NE: Circular RNAs are abundant, conserved, and associated with ALU repeats. RNA 19: 141-157, 2013.

10. Zhang Y, Zhang XO, Chen T, Xiang JF, Yin QF, Xing YH, Zhu S, Yang L and Chen LL: Circular intronic long noncoding RNAs. Mol Cell 51: 792-806, 2013.

11. Zhang XO, Wang HB, Zhang Y, Lu X, Chen LL and Yang L: Complementary sequence-mediated exon circularization. Cell 159: 134-147, 2014

12. Zhang Y, Xue W, Li X, Zhang J, Chen S, Zhang JL, Yang L and Chen LL: The biogenesis of nascent circular RNAs. Cell Rep 15: 611-624, 2016.

13. Liang D and Wilusz JE: Short intronic repeat sequences facilitate circular RNA production. Genes Dev 28: 2233-2247, 2014.

14. Conn SJ, Pillman KA, Toubia J, Conn VM, Salmanidis M, Phillips CA, Roslan S, Schreiber AW, Gregory PA and Goodall GJ: The RNA binding protein quaking regulates formation of circRNAs. Cell 160: 1125-34, 2015.

15. Aktaş T,Avşar Ilık İ, MaticzkaD, Bhardwaj V,Pessoa Rodrigues C Mittler G, Manke T, Backofen R and Akhtar A: DHX9 suppresses RNA processing defects originating from the Alu invasion of the human genome. Nature 544: 115-119, 2017.

16. Ashwal-Fluss R, Meyer M, Pamudurti NR, Ivanov A, Bartok O, Hanan M, Evantal N, Memczak S, Rajewsky N and Kadener S: circRNA biogenesis competes with pre-mRNA splicing. Mol Cell 56: 55-66, 2014.

17. Tang C, Xie Y, Yu T, Liu N, Wang Z, Woolsey RJ, Tang Y, Zhang $\mathrm{X}$, Qin $\mathrm{W}$, Zhang $\mathrm{Y}$, et al: $\mathrm{m}^{6} \mathrm{~A}$-dependent biogenesis of circular RNAs in male germ cells. Cell Res 30: 211-228, 2020.

18. Panda AC, Grammatikakis I, Munk R, Gorospe M and Abdelmohsen K: Emerging roles and context of circular RNAs Wiley Interdiscip Rev RNA 8: 10.1002/wrna.1386, 2017.

19. Aufiero S, van den Hoogenhof MMG, Reckman YJ, Beqqali A, van der Made I, Kluin J, Khan MAF, Pinto YM and Creemers EE: Cardiac circRNAs arise mainly from constitutive exons rather than alternatively spliced exons. RNA 24: 815-827, 2018

20. Li Z, Huang C, Bao C, Chen L, Lin M, Wang X, Zhong G, Yu B, $\mathrm{Hu}$ W, Dai L, et al: Exon-intron circular RNAs regulate transcription in the nucleus. Nat Struct Mol Biol 22: 256-264, 2015.

21. Abulizi R, Li B and Zhang CG: Circ_0071662, a novel tumor biomarker, suppresses bladder cancer cell proliferation and invasion by sponging miR-146b-3p. Oncol Res: Nov 18, 2019 (Epub ahead of print).

22. Zhang XO, Dong R, Zhang Y, Zhang JL, Luo Z, Zhang J, Chen LL and Yang L: Diverse alternative back-splicing and alternative splicing landscape of circular RNAs. Genome Res 26: 1277-1287,2016.

23. Ye T, Yang M, Huang D, Wang X, Xue B, Tian N, Xu X, Bao L, $\mathrm{Hu}$ H, Lv T and Huang Y: MicroRNA-7 as a potential therapeutic target for aberrant NF- $\mathrm{BB}$-driven distant metastasis of gastric cancer. J Exp Clin Cancer Res 38: 55, 2019.

24. Pan M, Li M, You C, Zhao F, Guo M, Xu H, Li L, Wang L and Dou J: Inhibition of breast cancer growth via miR-7 suppressing ALDH1A3 activity concomitant with decreasing breast cance stem cell subpopulation. J Cell Physiol 235: 1405-1416, 2020.

25. Liu X, Fu Q, Li S, Liang N, Li F, Li C, Sui C, Dionigi G and Sun H: LncRNA FOXD2-AS1 functions as a competing endogenous RNA to regulate TERT expression by sponging miR-7-5p in thyroid cancer. Front Endocrinol (Lausanne) 10: 207, 2019.

26. Hollensen AK, Andersen S, Hjorth K, Bak RO, Hansen TB, Kjems J, Aagaard L, Damgaard CK and Mikkelsen JG: Enhanced tailored MicroRNA sponge activity of RNA Pol II-transcribed TuD hairpins relative to ectopically expressed ciRS7-derived circRNAs. Mol Ther Nucleic Acids 13: 365-375, 2018 .

27. Zhang Z, Yang T and Xiao J: Circular RNAs: Promising biomarkers for human diseases. EBioMedicine 34: 267-274, 2018.

28. Du WW, Yang W, Liu E, Yang Z, Dhaliwal P and Yang BB: Foxo3 circular RNA retards cell cycle progression via forming ternary complexes with $\mathrm{p} 21$ and CDK2. Nucleic Acids Res 44: 2846-2858, 2016

29. Li X, Liu CX, Xue W, Zhang Y, Jiang S, Yin QF, Wei J, Yao RW Yang L and Chen LL: Coordinated circRNA biogenesis and function with NF90/NF110 in viral infection. Mol Cell 67: 214-227.e7, 2017

30. Yang Y, Fan X, Mao M, Song X, Wu P, Zhang Y, Jin Y, Yang Y, Chen LL, Wang Y, et al: Extensive translation of circular RNAs driven by $\mathrm{N}^{6}$-methyladenosine. Cell Res 27: 626-641, 2017.
31. Legnini I, Di Timoteo G, Rossi F, Morlando M, Briganti F, Sthandier O, Fatica A, Santini T, Andronache A, Wade M, et al: Circ-ZNF609 is a circular RNA that can be translated and functions in myogenesis. Mol Cell 66: 22-37.e9, 2017.

32. Erratum: Circ-DLG 1 promotes the proliferation of esophageal squamous cell carcinoma [Erratum]. Onco Targets Ther 12: 255 , 2018

33. Cao S, Chen G, Yan L, Li L and Huang X: Contribution of dysregulated circRNA_100876 to proliferation and metastasis of esophageal squamous cell carcinoma. Onco Targets Ther 11: 7385-7394, 2018

34. Xia W, Qiu M, Chen R, Wang S, Leng X, Wang J, Xu Y, Hu J, Dong G, Xu PL and Yin R: Circular RNA has circ 0067934 is upregulated in esophageal squamous cell carcinoma and promoted proliferation. Sci Rep 6: 35576, 2016

35. Zhong R, Chen Z, Mo T, Li Z and Zhang P: Potential role of circPVT1 as a proliferative factor and treatment target in esophageal carcinoma. Cancer Cell Int 19: 267, 2019

36. Wang Q, Zhang Q, Sun H, Tang W, Yang L, Xu Z, Liu Z, Jin H and Cao X: Circ-TTC17 promotes proliferation and migration of esophageal squamous cell carcinoma. Dig Dis Sci 64: 751-758, 2019.

37. Luo G, Li R and Li Z: CircRNA circFNDC3B promotes esophageal cancer progression via cell proliferation, apoptosis, and migration regulation. Int J Clin Exp Pathol 11: 4188-4196, 2018

38. Song H, Xu D, Shi P, He B, Li Z, Ji Y, Agbeko CK and Wang J: Upregulated circ RNA hsa_circ_0000337 promotes cell proliferation, migration, and invasion of esophageal squamous cell carcinoma. Cancer Manag Res 11: 1997-2006, 2019.

39. Shi Y, Guo Z, Fang N, Jiang W, Fan Y, He Y, Ma Z and Chen Y: hsa circ 0006168 sponges miR-100 and regulates mTOR to promote the proliferation, migration and invasion of esophageal squamous cell carcinoma. Biomed Pharmacother 117: 109151, 2019.

40. Shi N, Shan B, Gu B, Song Y, Chu H and Qian L: Circular RNA circ-PRKCI functions as a competitive endogenous RNA to regulate AKT3 expression by sponging miR-3680-3p in esophageal squamous cell carcinoma. J Cell Biochem 120: 10021-10030, 2019.

41. Liu Z, Hu G, Zhao Y, Xiao Z, Yan M and Ren M: Silence of cZNF292 suppresses the growth, migration, and invasion of human esophageal cancer Eca-109 cells via upregulating miR-206. J Cell Biochem 121: 2354-2362, 2020.

42. Wu Y, Zhi L, Zhao Y, Yang L and Cai F: Knockdown of circular RNA UBAP2 inhibits the malignant behaviours of esophageal squamous cell carcinoma by microRNA-422a/Rab10 axis Clin Exp Pharmacol Physiol: Feb 3, 2020 (Epub ahead of print).

43. Lan X, Liu X, Sun J, Yuan Q and Li J: CircRAD23B facilitates proliferation and invasion of esophageal cancer cells by sponging miR-5095. Biochem Biophys Res Commun 516: 357-364, 2019

44. Zhang Z, Lin W, Gao L, Chen K, Yang C, Zhuang L, Peng S, Kang M and Lin J: Hsa_circ_0004370 promotes esophageal cancer progression through miR-1294/LASP1 pathway. Biosci Rep 39: pii: BSR20182377, 2019.

45. Huang H, Wei L, Qin T, Yang N, Li Z and Xu Z: Circular RNA ciRS-7 triggers the migration and invasion of esophageal squamous cell carcinoma via miR-7/KLF4 and NF- $\kappa B$ signals Cancer Biol Ther 20: 73-80, 2019.

46. He Y, Mingyan E, Wang C, Liu G, Shi M and Liu S: CircVRK1 regulates tumor progression and radioresistance in esophageal squamous cell carcinoma by regulating miR-624-3p/PTEN/PI3K/AKT signaling pathway. Int J Biol Macromol 125: 116-123, 2019

47. Zhang Y, Liu H, Li W, Yu J, Li J, Shen Z, Ye G, Qi X and Li G: CircRNA_100269 is downregulated in gastric cancer and suppresses tumor cell growth by targeting miR-630. Aging (Albany NY) 9: 1585-1594, 2017.

48. Zhang J, Liu H, Hou L, Wang G, Zhang R, Huang Y, Chen X and Zhu J: Circular RNA_LARP4 inhibits cell proliferation and invasion of gastric cancer by sponging miR-424-5p and regulating LATS1 expression. Mol Cancer 16: 151, 2017.

49. Shao Y, Yang Y, Lu R, Xiao B, Ye G and Guo J: Identification of tissue-specific circRNA hsa circ 0000705 as an indicator for human gastric cancer. Int J Clin Exp Pathol 10: 3151-3156, 2017.

50. Shao Y, Chen L, Lu R, Zhang X, Xiao B, Ye G and Guo J: Decreased expression of hsa circ 0001895 in human gastric cancer and its clinical significances. Tumor Biol 39: $1010428317699125,2017$. 
51. Li WH, Song YC, Zhang H, Zhou ZJ, Xie X, Zeng QN, Guo K, Wang T, Xia P and Chang DM: Decreased expression of Hsa circ 00001649 in gastric cancer and its clinical significance. Dis Markers 2017: 4587698, 2017.

52. Huang M, He YR, Liang LC, Huang Q and Zhu ZQ: Circular RNA hsa_circ 0000745 may serve as a diagnostic marker for gastric cancer. World J Gastroenterol 23: 6330-6338, 2017.

53. Chen S, Li T, Zhao Q, Xiao B and Guo J: Using circular RNA hsa_circ_0000190 as a new biomarker in the diagnosis of gastric cancer. Clin Chim Acta 466: 167-171, 2017.

54. Chen J, Li Y, Zheng Q, Bao C, He J, Chen B, Lyu D, Zheng B, Xu Y, Long Z, et al: Circular RNA profile identifies circPVT1 as a proliferative factor and prognostic marker in gastric cancer. Cancer Lett 388: 208-219, 2017.

55. Zhu Z, Yu Z, Rong Z, Luo Z, Zhang J, Qiu Z and Huang C: The novel GINS4 axis promotes gastric cancer growth and progression by activating Rac1 and CDC42 Theranostics 9: 8294-8311, 2019.

56. Zhang X, Wang S, Wang H, Cao J, Huang X, Chen Z, Xu P, Sun G, Xu J, Lv J and Xu Z: Circular RNA circNRIP1 acts as a microRNA-149-5p sponge to promote gastric cancer progression via the AKT1/mTOR pathway. Mol Cancer 18: 20, 2019.

57. Zhang L, Song X, Chen X, Wang Q, Zheng X, Wu C and Jiang J: Circular RNA CircCACTIN promotes gastric cancer progression by sponging MiR-331-3p and regulating TGFBR1 expression. Int J Biol Sci 15: 1091-1103, 2019.

58. Wang Z, Ma K, Pitts S, Cheng Y, Liu X, Ke X, Kovaka S, Ashktorab H, Smoot DT, Schatz M, et al: Novel circular RNA circNF1 acts as a molecular sponge, promoting gastric cancer by absorbing miR-16. Endocr Relat Cancer 26: 265-277, 2019.

59. Shen F, Liu P, Xu Z, Li N, Yi Z, Tie X, Zhang Y and Gao L: CircRNA 001569 promotes cell proliferation through absorbing miR-145 in gastric cancer. J Biochem 165: 27-36, 2019.

60. Zhang H, Wang X, Huang H, Wang Y, Zhang F and Wang S: Hsa_circ 0067997 promotes the progression of gastric cancer by inhibition of miR-515-5p and activation of $X$ chromosome-linked inhibitor of apoptosis (XIAP). Artif Cells Nanomed Biotechnol 47: 308-318, 2019.

61. Wei J, Wang J, Gao X and Qi F: Identification of differentially expressed circRNAs and a novel hsa_circ_0000144 that promote tumor growth in gastric cancer. Cancer Cell Int 19: 268, 2019.

62. Ouyang Y, Li Y, Huang Y, Li X, Zhu Y, Long Y, Wang Y, Guo X and Gong K: CircRNA circPDSS1 promotes the gastric cancer progression by sponging miR-186-5p and modulating NEK2. J Cell Physiol 234: 10458-10469, 2019.

63. Liang M, Liu Z, Lin H, Shi B, Li M, Chen T, Qin L, Niu Q, Yu G, Jiang $H$ and Zhou X: High-throughput sequencing reveals circular RNA hsa_circ_0000592 as a novel player in the carcinogenesis of gastric carcinoma. Biosci Rep 39: pii: BSR 20181900, 2019.

64. Liang M, Huang G, Liu Z, Wang Q, Yu Z, Liu Z, Lin H, Li M Zhou X and Zheng Y: Elevated levels of hsa_circ 006100 in gastric cancer promote cell growth and metastasis via miR-195/GPRC5A signalling. Cell Prolif 52: e12661, 2019.

65. Huang S, Zhang X, Guan B, Sun P, Hong CT, Peng J, Tang S and Yang J: A novel circular RNA hsa_circ_0008035 contributes to gastric cancer tumorigenesis through targeting the miR-375/YBX1 axis. Am J Transl Res 11: 2455-2462, 2019

66. Wei J, Xu H, Wei W, Wang Z, Zhang Q, De W and Shu Y: circHIPK3 promotes cell proliferation and migration of gastric cancer by sponging miR-107 and regulating BDNF expression. Onco Targets Ther 13: 1613-1624, 2020.

67. Wang N, Lu K, Qu H, Wang H, Chen Y, Shan T, Ge X, Wei Y, Zhou P and Xia J: CircRBM33 regulates IL-6 to promote gastric cancer progression through targeting miR-149. Biomed Pharmacother 125: 109876, 2020

68. He Y, Wang Y, Liu L, Liu S, Liang L, Chen Y and Zhu Z: Circular RNA circ_0006282 contributes to the progression of gastric cancer by sponging miR-155 to upregulate the expression of FBXO22. Onco Targets Ther 13: 1001-1010, 2020.

69. Pan H, Pan J, Chen P, Gao J, Guo D, Yang Z, Ji L, Lv H, Guo Y and Xu D: WITHDRAWN: Circular RNA circUBA1 promotes gastric cancer proliferation and metastasis by acting as a competitive endogenous RNA through sponging miR-375 and regulating TEAD4. Cancer Lett: Feb 19, 2020 (Epub ahead of print).

70. Mo WL, Jiang JT, Zhang L, Lu QC, Li J, Gu WD, Cheng Y and Wang HT: Circular RNA hsa_circ_0000467 promotes the development of gastric cancer by competitively binding to MicroRNA miR-326-3p. Biomed Res Int 2020: 4030826, 2020.
71. Peng YK, Pu K, Su HX, Zhang J, Zheng Y, Ji R, Guo QH, Wang YP, Guan QL and Zhou YN: Circular RNA hsa circ 0010882 promotes the progression of gastric cancer via regulation of the PI3K/Akt/mTOR signaling pathway. Eur Rev Med Pharmacol Sci 24: 1142-1151, 2020.

72. Sun B, Sun H, Wang Q, Wang X, Quan J, Dong D and Lun Y: Circular RNA circMAN2B2 promotes growth and migration of gastric cancer cells by down-regulation of miR-145. J Clin Lab Anal: Feb 5, 2020 (Epub ahead of print)

73. Wei W, Mo X, Yan L, Huang M, Yang Y, Jin Q, Zhong H, Cao W, Wu K, Wu L, et al: Circular RNA profiling reveals that circRNA_104433 regulates cell growth by targeting miR-497-5p in gastric cancer. Cancer Manag Res 12: 15-30, 2020.

74. Zhao X, Zhong Q, Cheng X, Wang S, Wu R, Leng X and Shao L: miR-449c-5p availability is antagonized by circ-NOTCH1 for MYC-induced NOTCH1 upregulation as well as tumor metastasis and stemness in gastric cancer. J Cell Biochem: Jan 14, 2020 (Epub ahead of print).

75. Lu J,Zhang PY, Xie JW, Wang JB, Lin JX, Chen QY, Cao LL, Li P, Zheng $\mathrm{CH}$ and Huang CM: Circular RNA hsa circ 0006848 Related to ribosomal protein L6 Acts as a novel biomarker for early gastric cancer. Dis Markers 2019: 3863458, 2019.

76. Lu J, Zhang PY, Li P, Xie JW, Wang JB, Lin JX, Chen QY, Cao LL, Huang CM and Zheng CH: Circular RNA hsa circ 0001368 suppresses the progression of gastric cancer by regulating miR-6506-5p/FOXO3 axis. Biochem Biophys Res Commun 512: 29-33, 2019.

77. Liu H, Liu Y, Bian Z, Zhang J, Zhang R, Chen X, Huang Y, Wang Y and Zhu J: Circular RNA YAP1 inhibits the proliferation and invasion of gastric cancer cells by regulating the miR-367-5p/p27 Kip1 axis. Mol Cancer 17: 151, 2018

78. Li Q, Tang H, Hu F and Qin C: Circular RNA SMARCA5 inhibits gastric cancer progression through targeting the miR-346/FBXL2 axis. RSC Adv 9: 18277-18284, 2019

79. Fang J, Hong H, Xue X, Zhu X, Jiang L, Qin M, Liang H and Gao L: A novel circular RNA, circFAT1(e2), inhibits gastric cancer progression by targeting miR-548g in the cytoplasm and interacting with YBX1 in the nucleus. Cancer Lett 442: 222-232, 2019.

80. Wu L, Liu D and Yang Y: Enhanced expression of circular RNA circ-DCAF6 predicts adverse prognosis and promotes cell progression via sponging miR-1231 and miR-1256 in gastric cancer. Exp Mol Pathol 110: 104273, 2019.

81. Ding L, Zhao Y, Dang S, Wang Y, Li X, Yu X, Li Z, Wei J, Liu M and Li G: Circular RNA circ-DONSON facilitates gastric cancer growth and invasion via NURF complex dependent activation o transcription factor SOX4. Mol Cancer 18: 45, 2019.

82. He J, Chen J, Ma B, Jiang L and Zhao G: CircLMTK2 acts as a novel tumor suppressor in gastric cancer. Biosci Rep 39: pii: BSR20190363, 2019

83. Lu J, Wang YH, Huang XY, Xie JW, Wang JB, Lin JX, Chen QY, Cao LL, Huang CM, Zheng CH and Li P: circ-CEP85L suppresses the proliferation and invasion of gastric cancer by regulating NFKBIA expression via miR-942-5p. J Cell Physiol: Feb 5, 2020 (Epub ahead of print).

84. Zhang Z, Wu H, Chen Z, Li G and Liu B: Circular RNA ATXN7 promotes the development of gastric cancer through sponging miR-4319 and regulating ENTPD4. Cancer Cell Int 20: 25, 2020

85. Deng G, Mou T, He J, Chen D, Lv D, Liu H, Yu J, Wang S and Li G: Circular RNA circRHOBTB3 acts as a sponge for miR-654-3p inhibiting gastric cancer growth. J Exp Clin Cancer Res 39: 1, 2020

86. Cai J, Chen Z, Wang J, Wang J, Chen X, Liang L, Huang M, Zhang $\mathrm{Z}$ and Zuo $\mathrm{X}$ : circHECTD1 facilitates glutaminolysis to promote gastric cancer progression by targeting miR-1256 and activating $\beta$-catenin/c-Myc signaling. Cell Death Dis 10: 576, 2019.

87. Rong D, Lu C, Zhang B, Fu K, Zhao S, Tang W and Cao H: CircPSMC 3 suppresses the proliferation and metastasis of gastric cancer by acting as a competitive endogenous RNA through sponging miR-296-5p. Mol Cancer 18: 25, 2019.

88. Zhou LH, Yang YC, Zhang RY, Wang P, Pang MH and Liang LQ: CircRNA_0023642 promotes migration and invasion of gastric cancer cells by regulating EMT. Eur Rev Med Pharmacol Sci 22: 2297-2303, 2018.

89. Xie Y, Shao Y, Sun W, Ye G, Zhang X, Xiao B and Guo J: Downregulated expression of hsa_circ_0074362 in gastric cancer and its potential diagnostic values. Biomark Med 12: $11-20,2018$ 
90. Wang L, Shen J and Jiang Y: Circ 0027599/PHDLA1 suppresses gastric cancer progression by sponging miR-101-3p.1. Cell Biosci 8: 58, 2018

91. Tian M, Chen R, Li T and Xiao B: Reduced expression of circRNA hsa_circ_0003159 in gastric cancer and its clinical significance. J Clin Lab Anal 32, 2018.

92. Sun HD, Xu ZP, Sun ZQ, Zhu B, Wang Q, Zhou J, Jin H, Zhao A, Tang WW and Cao XF: Down-regulation of circPVRL3 promotes the proliferation and migration of gastric cancer cells. Sci Rep 8: 10111, 2018.

93. Sun H, Xi P, Sun Z, Wang Q, Zhu B, Zhou J, Jin H, Zheng W, Tang W, Cao H and Cao X: Circ-SFMBT2 promotes the proliferation of gastric cancer cells through sponging miR-182-5p to enhance CREB1 expression. Cancer Manag Res 10: 5725-5734, 2018.

94. Rong D, Dong C, Fu K, Wang H, Tang W and Cao H: Upregulation of circ_0066444 promotes the proliferation, invasion, and migration of gastric cancer cells. Onco Targets Ther 11: 2753-2761, 2018.

95. Liu M, Liu KD, Zhang L, Cai J, Yao HW, Bai YK and Zhang ZT: Circ_0009910 regulates growth and metastasis and is associated with poor prognosis in gastric cancer. Eur Rev Med Pharmacol Sci 22: 8248-8256, 2018.

96. Zhang H, Zhu L, Bai M, Liu Y, Zhan Y, Deng T, Yang H, Sun W, Wang X, Zhu K, et al: Exosomal circRNA derived from gastric tumor promotes white adipose browning by targeting the miR-133/PRDM16 pathway. Int J Cancer 144: 2501-2515, 2019

97. Hong Y, Qin H, Li Y, Zhang Y, Zhuang X, Liu L, Lu K, Li L, Deng $\mathrm{X}$, Liu $\mathrm{F}$, et al: FNDC3B circular RNA promotes the migration and invasion of gastric cancer cells via the regulation of E-cadherin and CD44 expression. J Cell Physiol 234 19895-19910, 2019

98. Zhang XY, Xu YY and Chen WY: Upregulation of circular SMAD7 inhibits tumorigenesis of gastric cancer by reversing epithelial-to-mesenchymal transition. Eur Rev Med Pharmacol Sci 24: 1152-1157, 2020.

99. Quan J, Dong D, Lun Y, Sun B, Sun H, Wang Q and Yuan G: Circular RNA circHIAT1 inhibits proliferation and epithelial-mesenchymal transition of gastric cancer cell lines through downregulation of miR-21. J Biochem Mol Toxicol 34: e22458, 2020.

100. Xue M, Li G, Fang X, Wang L, Jin Y and Zhou Q: hsa circ_0081143 promotes cisplatin resistance in gastric cancer by targeting miR-646/CDK6 pathway. Cancer Cell Int 19: 25, 2019.

101. Huang X, Li Z, Zhang Q, Wang W, Li B, Wang L, Xu Z, Zeng A, Zhang $X$, Zhang $X$, et al: Circular RNA AKT3 upregulates PIK3R1 to enhance cisplatin resistance in gastric cancer via miR-198 suppression. Mol Cancer 18: 71.2019.

102. Huang XX, Zhang Q, Hu H, Jin Y, Zeng AL, Xia YB and Xu L: A novel circular RNA circFN1 enhances cisplatin resistance in gastric cancer via sponging miR-182-5p. J Cell Biochem: Jan 2, 2020 (Epub ahead of print)

103. Fang Y, Pu N, Zhang L, Wu W and Lou W: Chemoradiotherapy is associated with improved survival for resected pancreatic adenosquamous carcinoma: A retrospective cohort study from the SEER database. Ann Transl Med 7: 522, 2019.

104. Yang J, Cong X, Ren M, Sun H, Liu T, Chen G, Wang Q, Li Z, Yu S and Yang Q: Circular RNA hsa_circRNA_0007334 is predicted to promote MMP7 and COL1A1 expression by functioning as a miRNA sponge in pancreatic ductal adenocarcinoma. J Oncol 2019: 7630894, 2019.

105. Qu S, Hao X, Song W, Niu K, Yang X, Zhang X, Shang R, Wang Q, Li H and Liu Z: Circular RNA circRHOT1 is upregulated and promotes cell proliferation and invasion in pancreatic cancer. Epigenomics 11: 53-63, 2019.

106. Zhu P, Ge N, Liu D, Yang F, Zhang K, Guo J, Liu X, Wang S, Wang $G$ and Sun S: Preliminary investigation of the function of hsa_circ_0006215 in pancreatic cancer. Oncol Lett 16: 603-611, 2018 .

107. An Y, Cai H, Zhang Y, Liu S, Duan Y, Sun D, Chen X and He X: circZMYM2 competed endogenously with miR-335-5p to regulate JMJD2C in pancreatic cancer. Cell Physiol Biochem 51: 2224-2236, 2018 .

108. Xing C, Ye H, Wang W, Sun M, Zhang J, Zhao Z and Jiang G: Circular RNA ADAM9 facilitates the malignant behaviours of pancreatic cancer by sponging miR-217 and upregulating PRSS3 expression. Artif Cells Nanomed Biotechnol 47: 3920-3928, 2019
109. Liu L, Liu FB, Huang M, Xie K, Xie QS, Liu CH, Shen MJ and Huang Q: Circular RNA ciRS-7 promotes the proliferation and metastasis of pancreatic cancer by regulating miR-7-mediated EGFR/STAT3 signaling pathway. Hepatobiliary Pancreat Dis Int 18: 580-586, 2019

110. Yang F, Liu DY, Guo JT, Ge N, Zhu P, Liu X, Wang S, Wang GX and Sun SY: Circular RNA circ-LDLRAD3 as a biomarker in diagnosis of pancreatic cancer. World J Gastroenterol 23 8345-8354, 2017.

111. Li J, Li Z, Jiang P, Peng M, Zhang X, Chen K, Liu H, Bi H, Liu X and Li X: Circular RNA IARS (circ-IARS) secreted by pancreatic cancer cells and located within exosomes regulates endothelial monolayer permeability to promote tumor metastasis. J Exp Clin Cancer Res 37: 177, 2018.

112. Ou ZL, Luo Z, Wei W, Liang S, Gao TL and Lu YB: Hypoxia-induced shedding of MICA and HIF1A-mediated immune escape of pancreatic cancer cells from NK cells: Role of circ 0000977/miR-153 axis. RNA Biol 16: 1592-1603, 2019.

113. Liu Y, Xia L, Dong L, Wang J, Xiao Q, Yu X and Zhu H: CircHIPK3 promotes gemcitabine (GEM) resistance in pancreatic cancer cells by sponging miR-330-5p and targets RASSF1. Cancer Manag Res 12: 921-929, 2020.

114. Zongyi Y and Xiaowu L: Immunotherapy for hepatocellular carcinoma. Cancer Lett 470: 8-17, 2020.

115. Busato D, Mossenta M, Baboci L, Di Cintio F, Toffoli G and Dal Bo M: Novel immunotherapeutic approaches for hepatocellular carcinoma treatment. Expert Rev Clin Pharmacol 12: 453-470, 2019.

116. Yu L, Gong X, Sun L, Zhou Q, Lu B and Zhu L: The circular RNA Cdrlas act as an oncogene in hepatocellular carcinoma through targeting miR-7 expression. PLoS One 11: e0158347, 2016.

117. Yao Z, Luo J, Hu K, Lin J, Huang H, Wang Q, Zhang P, Xiong Z, He C, Huang Z, et al: ZKSCAN1 gene and its related circular RNA (circZKSCAN1) both inhibit hepatocellular carcinoma cell growth, migration, and invasion but through different signaling pathways. Mol Oncol 11: 422-437, 2017.

118. Wang BB, Li JS, Liu YF and Xu Q: MicroRNA-200b suppresses the invasion and migration of hepatocellular carcinoma by downregulating RhoA and circRNA_000839. Tumour Biol 39: $1010428317719577,2017$.

119. Huang XY, Huang ZL, Xu YH, Zheng Q, Chen Z, Song W, Zhou J, Tang ZY and Huang XY: Comprehensive circular RNA profiling reveals the regulatory role of the circRNA-100338/miR-141-3p pathway in hepatitis B-related hepatocellular carcinoma. Sci Rep 7: 5428, 2017.

120. Fu L, Yao T, Chen Q, Mo X, Hu Y and Guo J: Screening differential circular RNA expression profiles reveals hsa_circ_0004018 is associated with hepatocellular carcinoma. Oncotarget 8: 58405-58416, 2017.

121. Zhu Q, Lu G, Luo Z, Gui F, Wu J, Zhang D and Ni Y: CircRNA circ 0067934 promotes tumor growth and metastasis in hepatocellular carcinoma through regulation of miR-1324/FZD5/Wnt/ $\beta$-catenin axis. Biochem Biophys Res Commun 497: 626-632, 2018.

122. Zhong L, Wang Y, Cheng Y, Wang W, Lu B, Zhu L and Ma Y: Circular RNA circC3P1 suppresses hepatocellular carcinoma growth and metastasis through miR-4641/PCK1 pathway. Biochem Biophys Res Commun 499: 1044-1049, 2018.

123. Zhang X, Zhou H, Jing W, Luo P, Qiu S, Liu X, Zhu M, Liang C, Yu M and Tu J: The circular RNA hsa_circ_0001445 regulates the proliferation and migration of hepatocellular carcinoma and may serve as a diagnostic biomarker. Dis Markers 2018: 3073467, 2018.

124. Zhang X, Xu Y, Qian Z, Zheng W, Wu Q, Chen Y, Zhu G, Liu Y, Bian Z,Xu W, et al: circRNA_104075 stimulates YAP-dependent tumorigenesis through the regulation of HNF4a and may serve as a diagnostic marker in hepatocellular carcinoma. Cell Death Dis 9: 1091, 2018.

125. Zhang $X$, Luo $P$, Jing $W$, Zhou $H$, Liang $C$ and Tu J: circSMAD2 inhibits the epithelial-mesenchymal transition by targeting miR-629 in hepatocellular carcinoma. Onco Targets Ther 11: 2853-2863, 2018

126. Zhang J, Liu H, Zhang R and Zhu J: Circular RNA SLC3A2 promotes hepatocellular carcinoma growth and invasion by sponging MIR-490-3P and upregulating PPM1F/AKT/GSK3/ $\beta$-catenin signaling pathway. Gastroenterology 154 (Suppl 1): S1154, 2018

127. Zhang C, Zhang C, Lin J and Wang H: Circular RNA Hsa Circ_0091579 serves as a diagnostic and prognostic marker for hepatocellular carcinoma. Cell Physiol Biochem 51: 290-300, 2018. 
128. Yu J, Xu QG, Wang ZG, Yang Y, Zhang L, Ma JZ, Sun SH, Yang $F$ and Zhou WP: Circular RNA cSMARCA5 inhibits growth and metastasis in hepatocellular carcinoma. J Hepatol 68: 1214-1227, 2018.

129. Wang B, Chen H, Zhang C, Yang T, Zhao Q, Yan Y, Zhang Y and $\mathrm{Xu}$ F: Effects of hsa circRBM23 on hepatocellular carcinoma cell viability and migration as produced by regulating miR-138 expression. Cancer Biother Radiopharm 33: 194-202, 2018.

130. Meng J, Chen S, Han JX, Qian B, Wang XR, Zhong WL, Qin Y, Zhang $\mathrm{H}$, Gao WF, Lei YY, et al: Twistl regulates vimentin through Cul2 Circular RNA to promote EMT in hepatocellular carcinoma. Cancer Res 78: 4150-4162, 2018.

131. Luo Z, Mao X and Cui W: Circular RNA expression and circPTPRM promotes proliferation and migration in hepatocellular carcinoma. Med Oncol 36: 86, 2019.

132. Li S, Gu H, Huang Y, Peng Q, Zhou R, Yi P, Chen R, Huang Z, Hu X, Huang Y and Tang D: Circular RNA 101368/miR-200a axis modulates the migration of hepatocellular carcinoma through HMGB1/RAGE signaling. Cell Cycle 17: 2349-2359, 2018.

133. Li MF, Li YH, He YH, Wang Q, Zhang Y, Li XF, Meng XM, Huang $\mathrm{C}$ and Li J: Emerging roles of hsa_circ_0005075 targeting miR-431 in the progress of HCC. Biomed Pharmacother 99: 848-858, 2018.

134. Gong Y, Mao J, Wu D, Wang X, Li L, Zhu L and Song R: Circ-ZEB1.33 promotes the proliferation of human HCC by sponging miR-200a-3p and upregulating CDK6. Cancer Cell Int 18: 116, 2018

135. Chen D, Zhang C, Lin J, Song X and Wang H: Screening differential circular RNA expression profiles reveal that hsa_circ_0128298 is a biomarker in the diagnosis and prognosis of hepatocellular carcinoma. Cancer Manag Res 10: 1275-1283, 2018.

136. Cai H, Hu B, Ji L, Ruan X and Zheng Z: Hsa_circ_0103809 promotes cell proliferation and inhibits apoptosis in hepatocellular carcinoma by targeting miR-490-5p/SOX2 signaling pathway. Am J Transl Res 10: 1690-1702, 2018.

137. Zou H, Xu X, Luo L, Zhang Y, Luo L, Yao Y, Xiang G, Huang X and Wang G: Hsa_circ_0101432 promotes the development of hepatocellular carcinoma (HCC) by adsorbing miR-1258 and miR-622. Cell Cycle 18: 2398-2413, 2019.

138. Zhu Y, Liu Y, Xiao B, Cai H, Liu M, Ma L, Yin H and Wang F: The circular RNA PVT1/miR-203/HOXD3 pathway promotes the progression of human hepatocellular carcinoma. Biol Open 8: pii: bio043687, 2019.

139. Zheng H, Chen T, Li C, Xu C, Ding C, Chen J, Ju S, Zhang Z, Liang Z, Cui Z and Zhao J: A circular RNA hsa_circ_0079929 inhibits tumor growth in hepatocellular carcinoma. Cancer Manag Res 11: 443-454, 2019

140. Zhang PF, Wei CY, Huang XY, Peng R, Yang X, Lu JC, Zhang C, Gao C, Cai JB, Gao PT, et al: Circular RNA circTRIM33-12 acts as the sponge of MicroRNA-191 to suppress hepatocellular carcinoma progression. Mol Cancer 18: 105, 2019.

141. Zhang J, Chang Y, Xu L and Qin L: Elevated expression of circular RNA circ_0008450 predicts dismal prognosis in hepatocellular carcinoma and regulates cell proliferation, apoptosis, and invasion via sponging miR-548p. J Cell Biochem 120: 9487-9494, 2019.

142. Zhang H, Deng T, Ge S, Liu Y, Bai M, Zhu K, Fan Q, Li J, Ning $\mathrm{T}$, Tian $\mathrm{F}$, et al: Exosome circRNA secreted from adipocytes promotes the growth of hepatocellular carcinoma by targeting deubiquitination-related USP7. Oncogene 38: 2844-2859, 2019.

143. Zhan W, Liao X, Chen Z, Li L, Tian T, Yu L, Wang W and Hu Q: Circular RNA hsa_circRNA_103809 promoted hepatocellular carcinoma development by regulating miR-377-3p/FGFR1/ERK axis. J Cell Physiol 235: 1733-1745, 2020.

144. Zhai Z, Fu Q, Liu C, Zhang X, Jia P, Xia P, Liu P, Liao S, Qin T and Zhang $\mathrm{H}$ : Emerging roles of hsa-circ-0046600 targeting the miR-640/HIF-1 $\alpha$ signalling pathway in the progression Of HCC. Onco Targets Ther 12: 9291-9302, 2019.

145. Yu J, Yang M, Zhou B, Luo J, Zhang Z, Zhang W and Yan Z: CircRNA-104718 acts as competing endogenous RNA and promotes hepatocellular carcinoma progression through microRNA-218-5p/TXNDC5 signaling pathway. Clin Sci (Lond) 133: 1487-1503, 2019.

146. Yang W, Liu Y, Gao R, Xiu Z and Sun T: Knockdown of cZNF292 suppressed hypoxic human hepatoma SMMC7721 cell proliferation, vasculogenic mimicry, and radioresistance. Cell Signal 60: 122-135, 2019
147. Xu L, Feng X, Hao X, Wang P, Zhang Y, Zheng X, Li L, Ren S, Zhang $M$ and Xu M: CircSETD3 (Hsa_circ_0000567) acts as a sponge for microRNA-421 inhibiting hepatocellular carcinoma growth. J Exp Clin Cancer Res 38: 98, 2019.

148. Xie B, Zhao Z, Liu Q, Wang X, Ma Z and Li H: CircRNA has circ 0078710 acts as the sponge of microRNA-31 involved in hepatocellular carcinoma progression. Gene 683: 253-261, 2019.

149. Weng Q, Chen M, Li M, Zheng YF, Shao G, Fan W, Xu XM and Ji J: Global microarray profiling identified hsa_circ_0064428 as a potential immune-associated prognosis biomarker for hepatocellular carcinoma. J Med Genet 56: 32-38, 2019.

150. Wang Z, Zhao Y, Wang Y and Jin C: Circular RNA circHIAT1 inhibits cell growth in hepatocellular carcinoma by regulating miR-3171/PTEN axis. Biomed Pharmacother 116: 108932, 2019.

151. Wang X, Wang X, Li W, Zhang Q, Chen J and Chen T: Up-regulation of hsa_circ_0000517 predicts adverse prognosis of hepatocellular carcinoma. Front Oncol 9: 1105, 2019.

152. Wang L, Long H, Zheng Q, Bo X, Xiao X and Li B: Circular RNA circRHOT1 promotes hepatocellular carcinoma progression by initiation of NR2F6 expression. Mol Cancer 18: 119, 2019.

153. Wang G, Liu W, Zou Y, Wang G, Deng Y, Luo J, Zhang Y, Li H, Zhang $\mathrm{Q}$, Yang $\mathrm{Y}$ and Chen G: Three isoforms of exosomal circPTGR1 promote hepatocellular carcinoma metastasis via the miR449a-MET pathway. EBioMedicine 40: 432-445, 2019.

154. Tan A, Li Q and Chen L: CircZFR promotes hepatocellular carcinoma progression through regulating miR-3619-5p/CTNNB1 axis and activating Wnt $/ \beta$-catenin pathway. Arch Biochem Biophys 661: 196-202, 2019

155. Sun S, Wang W, Luo X, Li Y, Liu B, Li X, Zhang B, Han S and Li X: Circular RNA circ-ADD3 inhibits hepatocellular carcinoma metastasis through facilitating EZH2 degradation via CDK1-mediated ubiquitination. Am J Cancer Res 9: 1695-1707, 2019.

156. Su Y, Xu C, Liu Y, Hu Y and Wu H: Circular RNA hsa circ 0001649 inhibits hepatocellular carcinoma progression via multiple miRNAs sponge. Aging (Albany NY) 11: 3362-3375, 2019.

157. Song C, Li D, Liu H, Sun H, Liu Z, Zhang L and Hu Y: The competing endogenous circular RNA ADAMTS14 suppressed hepatocellular carcinoma progression through regulating microRNA-572/regulator of calcineurin 1. J Cell Physiol 234: 2460-2470, 2019

158. Qiu L, Huang Y, Li Z, Dong X, Chen G, Xu H, Zeng Y, Cai Z, Liu X and Liu J: Circular RNA profiling identifies circADAMTS13 as a miR-484 sponge which suppresses cell proliferation in hepatocellular carcinoma. Mol Oncol 13: 441-455, 2019.

159. Pan H, Tang L, Jiang H, Li X, Wang R, Gao J and Li Q Enhanced expression of circ_0000267 in hepatocellular carcinoma indicates poor prognosis and facilitates cell progression by sponging miR-646. J Cell Biochem 120: $11350-11357,2019$.

160. Navarro A: Twist1 activated circRNA-10720 is a new player in hepatocellular carcinoma metastasis. Transl Cancer Res 8 (S2): S135-S140, 2019.

161. Ma Y, Zhang C, Zhang B, Yu H and Yu Q: circRNA of AR-suppressed PABPC1 91 bp enhances the cytotoxicity of natural killer cells against hepatocellular carcinoma via upregulating UL16 binding protein 1. Oncol Lett 17: 388-397, 2019.

162. Luo Y, Fu Y, Huang R, Gao M, Liu F, Gui R and Nie X CircRNA 101505 sensitizes hepatocellular carcinoma cells to cisplatin by sponging miR-103 and promotes oxidored-nitro domain-containing protein 1 expression. Cell Death Discov 5: 121, 2019.

163. Lin T, Dai Y, Guo X, Chen W, Zhao J, Cao L and Wu Z: Silencing of hsa_circ_0008450 represses hepatocellular carcinoma progression through regulation of microRNA-214-3p/EZH2 axis. Cancer Manag Res 11: 9133-9143, 2019.

164. Liang WC, Wong CW, Liang PP, Shi M, Cao Y, Rao ST, Tsui SK, Waye MM, Zhang Q, Fu WM and Zhang JF: Translation of the circular RNA circ $\beta$-catenin promotes liver cancer cell growth through activation of the Wnt pathway. Genome Biol 20: 84, 2019.

165. Li Z, Hu Y, Zeng Q, Wang H, Yan J, Li H and Yu Z: Circular RNA MYLK promotes hepatocellular carcinoma progression by increasing Rab23 expression by sponging miR-362-3p. Cancer Cell Int 19: 211, 2019. 
166. Li X and Shen M: Circular RNA hsa_circ 103809 suppresses hepatocellular carcinoma proliferation and invasion by sponging miR-620. Eur Rev Med Pharmacol Sci 23: 555-566, 2019.

167. Kou P, Zhang C, Lin J and Wang H: Circular RNA hsa_ circ_0078602 may have potential as a prognostic biomarker for patients with hepatocellular carcinoma. Oncol Lett 17: 2091-2098, 2019.

168. Ji L, Xu J, Lin Z, Mao Q, Zhang B and Cai X: Stabilization of UBQLN1 by circRNA_104797 mediates acquired sorafenib resistance in hepatocellular carcinoma. J Hepatol 70: E71-E73, 2019.

169. Guan Z, Tan J, Gao W, Li X, Yang Y, Li X, Li Y and Wang Q: Circular RNA hsa_circ_0016788 regulates hepatocellular carcinoma tumorigenesis through miR-486/CDK4 pathway. J Cell Physiol 234: 500-508, 2018.

170. Fu HW, Lin X, Zhu YX, Lan X, Kuang Y, Wang YZ, Ke ZG, Yuan $T$ and Chen P: Circ-IGF1R has pro-proliferative and anti-apoptotic effects in HCC by activating the PI3K/AKT pathway. Gene 716: 144031, 2019

171. Fang Z, Fan R, Lu Y, Sun Y, Zhao C, Liu L and Liu X: Circular RNA hsa circ 0002124 promotes hepatocellular carcinoma cell proliferation through the MAPK pathway. Transl Cancer Res 8: 367-378, 2019.

172. Chen Z, Zuo X, Pu L, Zhang Y, Han G, Zhang L, Wu J and Wang X: circLARP4 induces cellular senescence through regulating miR-761/RUNX3/p53/p21 signaling in hepatocellular carcinoma. Cancer Sci 110: 568-581, 2019.

173. Chen Q, Chen Z, Cao S, Guo B, Chen Y, Feng Z, Wang J, Guo G, Chen X and Huang X: Role of CircRNAs_100395 in proliferation and metastases of liver cancer. Med Sci Monit 25: 6181-6192, 2019

174. Chen H, Liu S, Li M, Huang P and Li X: circ_0003418 inhibits tumorigenesis and cisplatin chemoresistance through Wnt/ $\beta$-catenin pathway in hepatocellular carcinoma. Onco Targets Ther 12: 9539-9549, 2019.

175. Cao S, Wang G, Wang J, Li C and Zhang L: Hsa_circ_101280 promotes hepatocellular carcinoma by regulating miR-375/JAK2. Immunol Cell Biol 97: 218-228, 2019.

176. Zhao M, Dong G, Meng Q, Lin S and Li X: Circ-HOMER1 enhances the inhibition of miR-1322 on CXCL6 to regulate the growth and aggressiveness of hepatocellular carcinoma cells. J Cell Biochem: Feb 9, 2020 (Epub ahead of print).

177. Yu Q, Dai J and Shu M: Hsa_circ_0003645 shows an oncogenic role by sponging microRNA- 1299 in hepatocellular carcinoma cells. J Clin Lab Anal: Feb 28, 2020 (Epub ahead of print).

178. Xiao Y, Liu G, Sun Y, Gao Y, Ouyang X, Chang C, Gong L and Yeh S: Targeting the estrogen receptor alpha $(E R \alpha)$-mediated circ-SMG1.72/miR-141-3p/Gelsolin signaling to better suppress the HCC cell invasion. Oncogene 39: 2493-2508, 2020.

179. Wei X, Zheng W, Tian P, He Y, Liu H, Peng M, Li X and Liu X: Oncogenic hsa_circ_0091581 promotes the malignancy of HCC cell through blocking miR-526b from degrading c-MYC mRNA. Cell Cycle 19: 817-824, 2020.

180. Pu J, Wang J, Li W, Lu Y, Wu X, Long X, Luo C and Wei H: hsa_circ_0000092 promotes hepatocellular carcinoma progression through up-regulating HN1 expression by binding to microRNA-338-3p. J Cell Mol Med: Feb 20, 2020 (Epub ahead of print).

181. Liu D, Kang H, Gao M, Jin L, Zhang F, Chen D, Li M and Xiao L: Exosome-transmitted circ MMP2 promotes hepatocellular carcinoma metastasis by upregulating MMP2. Mol Oncol: Jan 14, 2020 (Epub ahead of print)

182. Liu B, Yang G, Wang X, Liu J, Lu Z, Wang Q, Xu B, Liu Z and Li J: CircBACH1 (hsa_circ_0061395) promotes hepatocellular carcinoma growth by regulating p27 repression via HuR. J Cell Physiol: Jan 31, 2020 (Epub ahead of print).

183. Li Z, Liu Y, Yan J, Zeng Q, Hu Y, Wang H, Li H, Li J and Yu Z: Circular RNA hsa_circ_0056836 functions an oncogenic gene in hepatocellular carcinoma through modulating miR-766-3p/FOSL2 axis. Aging (Albany NY) 12: 2485-2497, 2020.

184. Gao J, Dai C, Yu X, Yin X-B and Zhou F: Circ-TCF4.85 silencing inhibits cancer progression through microRNA-486-5p-targeted inhibition of ABCF2 in hepatocellular carcinoma. Mol Oncol 14: 447-461, 2020.

185. Ding Z, Guo L, Deng Z and Li P: Circ-PRMT5 enhances the proliferation, migration and glycolysis of hepatoma cells by targeting miR-188-5p/HK2 axis. Ann Hepatol: Jan 27, 2020 (Epub ahead of print).
186. Chen W, Quan Y, Fan S, Wang H, Liang J, Huang L, Chen L, Liu Q, He P and Ye Y: Exosome-transmitted circular RNA hsa circ 0051443 suppresses hepatocellular carcinoma progression. Cancer Lett 475: 119-128, 2020.

187. Yao Z, Xu R, Yuan L, Xu M, Zhuang H, Li Y, Zhang Y and Lin N: Circ_0001955 facilitates hepatocellular carcinoma (HCC) tumorigenesis by sponging miR-516a-5p to release TRAF6 and MAPK11. Cell Death Dis 10: 945-945, 2019.

188. Chen L, Kong R, Wu C, Wang S, Liu Z, Liu S, Li S, Chen T, Mao C and Liu S: Circ-MALAT1 functions as Both an mRNA translation brake and a microRNA sponge to promote self-renewal of hepatocellular cancer stem cells. Adv Sci (Weinh) 7: 1900949, 2019.

189. Sun P, Fan X, Hu X, Fu X, Wei Q and Zang Y: circPCNX and pecanex promote hepatocellular carcinoma cell viability by inhibiting miR-506. Cancer Manag Res 11: 10957-10967, 2019.

190. Liu Z, Yu Y, Huang Z, Kong Y, Hu X, Xiao W, Quan J and Fan X: CircRNA-5692 inhibits the progression of hepatocellular carcinoma by sponging miR-328-5p to enhance DAB2IP expression. Cell Death Dis 10: 900, 2019.

191. Fu Y, Cai L, Lei X and Wang D: Circular RNA ABCB10 promotes hepatocellular carcinoma progression by increasing HMG20A expression by sponging miR-670-3p. Cancer Cell Int 19: 338, 2019

192. Hu ZQ, Zhou SL, Li J, Zhou ZJ, Wang PC, Xin HY, Mao L, Luo CB, Yu SY, Huang XW, et al: Circular RNA sequencing identifies CircASAP1 as a key regulator in hepatocellular carcinoma metastasis. Hepatology: Dec 15, 2019 (Epub ahead of print).

193. Xu S, Zhan M, Jiang C, He M, Yang L, Shen H, Huang S, Huang X, Lin R, Shi Y, et al: Genome-wide CRISPR screen identifies ELP5 as a determinant of gemcitabine sensitivity in gallbladder cancer. Nat Commun 10: 5492, 2019.

194. Wang S, Zhang Y, Cai Q, Ma M, Jin LY, Weng M, Zhou D, Tang Z, Wang JD and Quan Z: Circular RNA FOXP1 promotes tumor progression and Warburg effect in gallbladder cancer by regulating PKLR expression. Mol Cancer 18: 145, 2019.

195. Kai D, Yannian L, Yitian C, Dinghao G, Xin Z and Wu J: Circular RNA HIPK3 promotes gallbladder cancer cell growth by sponging microRNA-124. Biochem Biophys Res Commun 503: 863-869, 2018.

196. Huang X, He M, Huang S, Lin R, Zhan M, Yang D, Shen H, $\mathrm{Xu}$ S, Cheng W, Yu J, et al: Circular RNA circERBB2 promotes gallbladder cancer progression by regulating PA2G4-dependent rDNA transcription. Mol Cancer 18: 166, 2019.

197. Ahnen DJ and Patel SG: Cost-effectiveness and national effects of initiating colorectal cancer screening for average-risk persons at age 45 years instead of 50 years. Gastroenterology 157: 1691-1692, 2019.

198. Wang X, Zhang Y, Huang L, Zhang J, Pan F, Li B, Yan Y, Jia B, Liu H, Li S and Zheng W: Decreased expression of hsa circ 001988 in colorectal cancer and its clinical significances. Int J Clin Exp Pathol 8: 16020-16025, 2015.

199. Xie H, Ren X, Xin S, Lan X, Lu G, Lin Y, Yang SS, Zeng ZC, Liao WT, Ding YQ and Liang L: Emerging roles of circRNA_001569 targeting miR-145 in the proliferation and invasion of colorectal cancer. Oncotarget 7: 26680-26691, 2016

200. Guo JN, Li J, Zhu CL, Feng WT, Shao JX, Wan L, Huang MD and He JD: Comprehensive profile of differentially expressed circular RNAs reveals that hsa circ 0000069 is upregulated and promotes cell proliferation, migration, and invasion in colorectal cancer. Onco Targets Ther 9: 7451-7458, 2016.

201. Zhuo F, Lin H, Chen Z, Huang Z and Hu J: The expression profile and clinical significance of circRNA0003906 in colorectal cancer. Onco Targets Ther 10: 5187-5193, 2017.

202. Zhu M, Xu Y, Chen Y and Yan F: Circular BANP, an upregulated circular RNA that modulates cell proliferation in colorectal cancer. Biomed Pharmacother 88: 138-144, 2017.

203. Zhang XL, Xu LL and Wang F: Hsa_circ_0020397 regulates colorectal cancer cell viability, apoptosis and invasion by promoting the expression of the miR-138 targets TERT and PD-L1. Cell Biol Int 41: 1056-1064, 2017.

204. Zhang R, Xu J, Zhao J and Wang X: Silencing of hsa circ_0007534 suppresses proliferation and induces apoptosis in colorectal cancer cells. Eur Rev Med Pharmacol Sci 22: $118-126,2018$

205. Zeng K, Chen X, Xu M, Liu X, Hu X, Xu T, Sun H, Pan Y, He B and Wang S: CircHIPK3 promotes colorectal cancer growth and metastasis by sponging miR-7. Cell Death Dis 9: 417, 2018. 
206. Yuan Y, Liu W, Zhang Y, Zhang Y and Sun S: CircRNA circ_0026344 as a prognostic biomarker suppresses colorectal cancer progression via microRNA-21 and microRNA-31. Biochem Biophys Res Commun 503: 870-875, 2018.

207. Wu L, Xia J, Yang J, Shi Y, Xia H, Xiang X and Yu X: Circ-ZNF609 promotes migration of colorectal cancer by inhibiting Gli1 expression via microRNA-150. J BUON 23: 1343-1349, 2018.

208. Li XN, Wang ZJ, Ye CX, Zhao BC, Li ZL and Yang Y: RNA sequencing reveals the expression profiles of circRNA and indicates that circDDX17 acts as a tumor suppressor in colorectal cancer. J Exp Clin Cancer Res 37: 325, 2018.

209. Li X, Wang J, Zhang C, Lin C, Zhang J, Zhang W, Zhang W, Lu Y, Zheng L and Li X: Circular RNA circITGA7 inhibits colorectal cancer growth and metastasis by modulating the Ras pathway and upregulating transcription of its host gene ITGA7. J Pathol 246: 166-179, 2018

210. Jin Y, Yu LL, Zhang B, Liu CF and Chen Y: Circular RNA hsa_circ_0000523 regulates the proliferation and apoptosis of colorectal cancer cells as miRNA sponge. Braz J Med Biol Res 51: e7811, 2018.

211. He JH, Li YG, Han ZP, Zhou JB, Chen WM, Lv YB, He ML, Zuo JD and Zheng L: The CircRNA-ACAP2/Hsa-miR-21-5p/ Tiam1 regulatory feedback circuit affects the proliferation migration, and invasion of colon cancer SW480 cells. Cell Physiol Biochem 49: 1539-1550, 2018.

212. Fang G, Ye BL, Hu BR, Ruan XJ and Shi YX: CircRNA_100290 promotes colorectal cancer progression through miR-516b-induced downregulation of FZD4 expression and Wnt/ $\beta$-catenin signaling. Biochem Biophys Res Commun 504: 184-189, 2018.

213. Bian L, Zhi X, Ma L, Zhang J, Chen P, Sun S, Li J, Sun Y and Qin J: Hsa_circRNA_103809 regulated the cell proliferation and migration in colorectal cancer via miR-532-3p/FOXO4 axis. Biochem Biophys Res Commun 505: 346-352, 2018.

214. Geng Y, Zheng X, Hu W, Wang Q, Xu Y, He W, Wu C, Zhu D, Wu C and Jiang J: Hsa_circ_0009361 acts as the sponge of miR-582 to suppress colorectal cancer progression by regulating APC2 expression. Clin Sci (Lond) 133: 1197-1213, 2019.

215. Jin C, Wang A, Liu L, Wang G and Li G: Hsa_circ_0136666 promotes the proliferation and invasion of colorectal cancer through miR-136/SH2B1 axis. J Cell Physiol 234: 7247-7256, 2019.

216. Li H, Jin X, Liu B, Zhang P, Chen W and Li Q: CircRNA CBL.11 suppresses cell proliferation by sponging miR-6778-5p in colorectal cancer. BMC Cancer 19: 826, 2019.

217. Li R, Wu B, Xia J, Ye L and Yang X: Circular RNA hsa circRNA 102958 promotes tumorigenesis of colorectal cancer via miR-585/CDC25B axis. Cancer Manag Res 11: 6887-6893, 2019.

218. Li XN, Wang ZJ, Ye CX, Zhao BC, Huang XX and Yang L: Circular RNA circVAPA is up-regulated and exerts oncogenic properties by sponging miR-101 in colorectal cancer. Biomed Pharmacother 112: 108611, 2019.

219. Li Y, Li C, Xu R, Wang Y, Li D and Zhang B: A novel circFMN2 promotes tumor proliferation in CRC by regulating the miR-1182/hTERT signaling pathways. Clin Sci (Lond) 133: 2463-2479, 2019

220. Lu C, Jiang W, Hui B, Rong D, Fu K, Dong C, Tang W and Cao H: The circ_0021977/miR-10b-5p/P21 and P53 regulatory axis suppresses proliferation, migration, and invasion in colorectal cancer. J Cell Physiol 235: 2273-2285, 2020.

221. Min L, Wang H and Zeng Y: CircRNA_104916 regulates migration, apoptosis and epithelial-mesenchymal transition in colon cancer cells. Front Biosci (Landmark Ed) 24: 819-832, 2019.

222. Pan B, Qin J, Liu X, He B, Wang X, Pan Y, Sun H, Xu T, $\mathrm{Xu} \mathrm{M}$, Chen $\mathrm{X}$, et al: Identification of serum exosomal hsa-circ-0004771 as a novel diagnostic biomarker of colorectal cancer. Front Genet 10: 1036, 2019.

223. Shen T, Cheng X, Liu X, Xia C, Zhang H, Pan D, Zhang X and Li Y: Circ_0026344 restrains metastasis of human colorectal cancer cells via miR-183. Artif Cells Nanomed Biotechnol 47: 4038-4045, 2019.

224. Tian J, Xi X, Wang J, Yu J, Huang Q, Ma R, Zhang X, Li H and Wang L: CircRNA hsa circ 0004585 as a potential biomarker for colorectal cancer. Cancer Manag Res 11: 5413-5423, 2019.
225. Yang F, Fang E, Mei H, Chen Y, Li H, Li D, Song H, Wang J, Hong M, Xiao W, et al: Cis-acting circ-CTNNB1 promotes $\beta$-catenin signaling and cancer progression via DDX3-mediated transactivation of YY1. Cancer Res 79: 557-571, 2019.

226. Yang G, Zhang T, Ye J, Yang J, Chen C, Cai S and Ma J: Circ-ITGA7 sponges miR-3187-3p to upregulate ASXL1, suppressing colorectal cancer proliferation. Cancer Manag Res 11: 6499-6509, 2019.

227. Zhang J, Liu H, Zhao P, Zhou H and Mao T: Has_circ_0055625 from circRNA profile increases colon cancer cell growth by sponging miR-106b-5p. J Cell Biochem 120: 3027-3037, 2019.

228. Zhang X, Zhao Y, Kong P, Han M and Li B: Expression of circZNF609 is down-regulated in colorectal cancer tissue and promotes apoptosis in colorectal cancer cells by upregulating p53. Med Sci Monit 25: 5977-5985, 2019.

229. Zhou C, Liu HS, Wang FW, Hu T, Liang ZX, Lan N, He XW, Zheng XB, Wu XJ, Xie D, et al: circCAMSAP1 promotes tumor growth in colorectal cancer via the miR-328-5p/E2F1 axis. Mol Ther 28: 914-928, 2020.

230. Zhu CL, Sha X, Wang Y, Li J, Zhang MY, Guo ZY, Sun SA and He JD: Circular RNA hsa_circ_0007142 Is upregulated and targets miR-103a-2-5p in colorectal cancer. J Oncol 2019: 9836819, 2019.

231. Chen HY, Li XN, Ye CX, Chen ZL and Wang ZJ: Circular RNA circHUWE1 is upregulated and promotes cell proliferation, migration and invasion in colorectal cancer by sponging miR-486. Onco Targets Ther 13: 423-434, 2020.

232. Li W, Xu Y, Wang X, Cao G, Bu W, Wang X, Fang Z, Xu Y, Dong $\mathrm{M}$ and Tao Q: circCCT3 modulates vascular endothelial growth factor A and Wnt signaling to enhance colorectal cancer metastasis through sponging miR-613. DNA Cell Biol 39: $118-125,2020$

233. Pei FL, Cao MZ and Li YF: Circ_0000218 plays a carcinogenic role in colorectal cancer progression by regulating miR-139-3p/RAB1A axis. J Biochem 167: 55-65, 2020.

234. Ren C, Zhang Z, Wang S, Zhu W, Zheng P and Wang W: Circular RNA hsa_circ 0001178 facilitates the invasion and metastasis of colorectal cancer through upregulating ZEB1 via sponging multiple miRNAs. Biol Chem 401: 487-496, 2020

235. Wang $X$, Zhang $H$, Yang $H$, Bai M, Ning T, Deng T, Liu R, Fan $\mathrm{Q}$, Zhu K, Li J, et al: Exosome-delivered circRNA promotes glycolysis to induce chemoresistance through the miR-122-PKM2 axis in colorectal cancer. Mol Oncol 14: $539-555,2020$

236. Yang B, Du K, Yang C, Xiang L, Xu Y, Cao C, Zhang J and Liu W: CircPRMT5 circular RNA promotes proliferation of colorectal cancer through sponging miR-377 to induce E2F3 expression. J Cell Mol Med 24: 3431-3437, 2020.

237. Yang H, Li X, Meng Q, Sun H, Wu S, Hu W, Liu G, Li X, Yang Y and Chen R: CircPTK2 (hsa circ 0005273) as a novel therapeutic target for metastatic colorectal cancer. Mol Cancer 19: 13,2020 .

238. Yang L, Sun H, Liu X, Chen J, Tian Z, Xu J, Xiang B and Qin B: Circular RNA hsa_circ_0004277 contributes to malignant phenotype of colorectal cancer by sponging miR-512-5p to upregulate the expression of PTMA. J Cell Physiol: Jan 21, 2020 (Epub ahead of print).

239. Zhao $\mathrm{H}$, Chen $\mathrm{S}$ and $\mathrm{Fu} \mathrm{Q}$ : Exosomes from $\mathrm{CD}_{133^{+}}$cells carrying circ-ABCC1 mediate cell stemness and metastasis in colorectal cancer. J Cell Biochem 121: 3286-3297, 2020.

240. Joensuu H, Vehtari A, Riihimäki J, Nishida T, Steigen SE, Brabec P, Plank L, Nilsson B, Cirilli C, Braconi C, et al: Risk of recurrence of gastrointestinal stromal tumour after surgery: An analysis of pooled population-based cohorts. Lancet Oncol 13: 265-274, 2012.

241. Jia N, Tong H, Zhang Y, Katayama H, Wang Y, Lu W, Zhang S and Wang J: CeRNA expression profiling identifies KIT-Related circRNA-miRNA-mRNA networks in gastrointestinal stromal tumour. Front Genet 10: 825, 2019.

242. Anastasiadou E, Jacob LS and Slack FJ: Non-coding RNA networks in cancer. Nat Rev Cancer 18: 5-18, 2018

243. Lewis BP, Burge CB and Bartel DP: Conserved seed pairing, often flanked by adenosines, indicates that thousands of human genes are microRNA targets. Cell 120: 15-20, 2005.

244. Xu B, Yang T, Wang Z, Zhang Y, Liu S and Shen M: CircRNA CDR1as/miR-7 signals promote tumor growth of osteosarcoma with a potential therapeutic and diagnostic value. Cancer Manag Res 10: 4871-4880, 2018. 
245. Pan H, Li T, Jiang Y, Pan C, Ding Y, Huang Z, Yu H and Kong D: Overexpression of circular RNA ciRS-7 abrogates the tumor suppressive effect of miR-7 on gastric cancer via PTEN/PI3K/AKT signaling pathway. J Cell Biochem 119: 440-446, 2018

246. Kabir TD, Ganda C, Brown RM, Beveridge DJ, Richardson KL, Chaturvedi V, Candy P, Epis M, Wintle L, Kalinowski F, et al: A microRNA-7/growth arrest specific 6/TYRO3 axis regulates the growth and invasiveness of sorafenib-resistant cells in human hepatocellular carcinoma. Hepatology 67: 216-231, 2018.

247. Li H, Fan J, Zhao Y, Zhang X, Dai B, Zhan J, Yin Z, Nie X, Fu XD, Chen C and Wang DW: Nuclear miR-320 mediates diabetes-induced cardiac dysfunction by activating transcription of fatty acid metabolic genes to cause lipotoxicity in the heart. Circ Res 125: 1106-1120, 2019.
248. Yuan H, Chen Z, Bai S, Wei H, Wang Y, Ji R, Guo Q, Li Q, Ye Y, Wu J, et al: Molecular mechanisms of lncRNA SMARCC2/miR-551b-3p/TMPRSS4 axis in gastric cancer. Cancer Lett 418: 84-96, 2018

249. Ding J, Zhao J, Huan L, Liu Y, Qiao Y, Wang Z, Chen Z, Huang S, Zhao Y and He X: Inflammation-induced LINC00665 increases the malignancy through activating $\mathrm{PKR} / \mathrm{NF}-\kappa \mathrm{B}$ pathway in hepatocellular carcinoma. Hepatology: Feb 21, 2020 (Epub ahead of print).

(c) (i) $(9)$ This work is licensed under a Creative Commons Attribution-NonCommercial-NoDerivatives 4.0 International (CC BY-NC-ND 4.0) License. 